\title{
The evaluation of an integrated Growth \& Goals Module to better equip students with learning skills in postsecondary courses: systematic, scalable, and explicit
}

\author{
Emily K. O'Connor ${ }^{1}$, Kevin Roy ${ }^{2}$, Ellyssa Walsh ${ }^{1}$, Denzel Huang ${ }^{1}$, Danny Yu Jia Ke ${ }^{1}$, Elizabeth \\ Campbell Brown ${ }^{3}$, Katherine A. Moreau ${ }^{4}$, and Alison B. Flynn ${ }^{5 *}$ \\ ${ }^{1}$ Faculty of Science, University of Ottawa, Ottawa, ON, Canada \\ ${ }^{2}$ Faculty of Medicine, University of Ottawa, Ottawa, ON, Canada \\ ${ }^{3}$ Teaching and Learning Support Service, University of Ottawa, Ottawa, ON, Canada \\ ${ }^{4}$ Faculty of Education, University of Ottawa, Ottawa, ON, Canada \\ ${ }^{5}$ Department of Chemistry \& Biomolecular Sciences, Faculty of Science, University of Ottawa, \\ Ottawa, ON, Canada
}

- Corresponding author

- Email alison.flynn@uOttawa.ca 


\begin{abstract}
In this dynamic and rapidly changing world, students need to be able to continually learn and adapt throughout their lives. However, most students spend years in formal education settings without being explicitly taught how to learn effectively. To reach our goal of explicitly and effectively equipping all students with learning skills, we developed and evaluated a Growth \& Goals module. The module is an Open Education Resource for postsecondary students that educators integrate in their courses to teach core learning skills of metacognition, goal-setting, growth mindset, and mindfulness. Over 5000 students at ten institutions have now used the module. In the present study, we evaluated the module using a Practical Participatory Evaluation approach and the 4-level Kirkpatrick Evaluation model. To answer ten questions aligned with the Kirkpatrick model, we collected data from 1845 students and 5 educators from nine undergraduate courses in science, engineering, and mathematics, which were used to investigate ten research questions aligned with Kirkpatrick's four evaluation levels. For Level 1 (Reaction), students and educators reported high satisfaction and gave constructive suggestions that centred on expanding the module. The training was new to $88 \%$ of students. Most completion rates were over $75 \%$ when professors provided an incentive $(\geq 1 \%)$. Students in some demographics used the module less than others: lower-achieving, first-generation university students, from outside the Ottawa-Gatineau area, male, and in certain programs. In Level 2 (Learning), students' metacognitive skills increased throughout the semester. They could identify SMART goals (Specific, Measurable, Accountable, Reachable, and Time-specific) and differentiate growth/fixed mindset statements. At Level 3 (Behaviour), students applied the module within the originating course, indicated their intent to use the module in the future, and a survey of a subsample indicated that most students used or intended to use the module in a new course. Most educators created course-level learning outcomes for the first time to integrate with the module. As an Open Education Resource with a nearly complete "plug-andplay" format, using the module required little time and low technological skills of students and educators; however, greater support, incentives, and rewards could be provided. Research and development require sustained resources. Finally, in Level 4 (Results), educators have used the module in courses in a number of disciplines, including sciences, engineering, mathematics, education, and psychology. The module addresses institutional goals of transformational learning and agility, as well as two provincial degree level expectations that are rarely explicitly taught in courses. In summary, the Growth \& Goals module explicitly teaches core learning skills in a way that is systematic, scalable, and explicit for science, engineering, and mathematics courses, with a potential to expand to any discipline.
\end{abstract}

\title{
Keywords
}

Learning skills, metacognition, goal-setting, growth mindset, mindfulness, postsecondary, STEM education, module, scalable, systematic, consistent, open education resource, evaluation, Practical Participatory Evaluation, Kirkpatrick Evaluation 


\section{Introduction}

In this dynamic and rapidly changing world, students need to be able to continually learn and adapt throughout their lives as well as well beyond the time they spend in formal education (1). However, most students spend years in formal education settings without being explicitly taught how to learn effectively. The recent pivot to remote education caused by the pandemic has revealed existing deficiencies in the postsecondary education system all too clearly. Without having the essential learning skills to adapt, including well-defined learning strategies (1), students resort to working harder rather than more strategically, resulting in increased stress and significant mental health and academic impacts (2-4) Moreover, equity gaps widen as those fortunate students living with support continue to thrive, while others fall further behind in their studies or drop out altogether $(2,5,6)$.

Some existing approaches to explicitly teach learning skills show beneficial impacts for students, including reducing equity gaps (7-16). However, there is a significant barrier to making these approaches systematic, scalable, and consistent for all students. For example, interventions may reach some students in some programs (e.g., first year seminar courses) or those in serious need (e.g., remedial programs through academic services). Courses and workshops on learning skills that are offered separately from the courses within students' programs may seem remote, not applicable, or as yet another thing to add to an already full schedule. These interventions require the educator to have expertise in the constructs being addressed (e.g., metacognition, goal-setting, mindfulness), including how to teach these constructs. However, most educators are experts in their own discipline and not in making these constructs explicit $(17,18)$.

\section{Our approach}

Our goal is to develop an approach that can effectively equip all students with learning skills, particularly of metacognition, goal-setting, growth mindset, and mindfulness. To accomplish this goal, we sought an approach that was: integrated in courses, scalable, independent of educator expertise to incorporate, transferable to any discipline and year of study, and created with an inclusive design for learning $(19,20)$. We also aim for an approach that would explicitly and consistently teach and assess learning skills, be adaptable, and be linked to the disciplinary context-the course's intended learning outcomes (ILOs are the knowledge, skills, and values that students should demonstrate by the end of a learning period-e.g., course or program). We therefore developed the Growth \& Goals Module for postsecondary students as an Open Education Resource that educators and students can use almost as is-requiring only incorporation of the course's intended learning outcomes (Fig 1) (21-24). Students complete the module throughout a given postsecondary course. The module contains a combination of theory and practice, including phases of reflection, goal-setting, planning, and acting (i.e., selfregulated learning). 


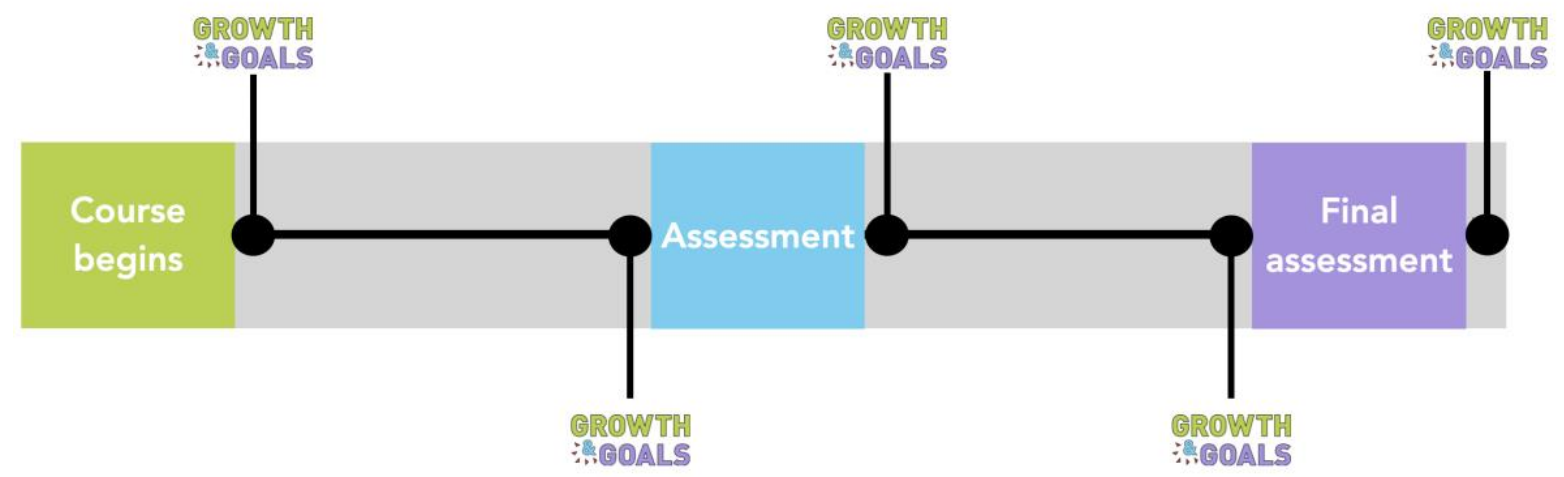

Fig 1. Growth \& Goals Module: a course-integrated learning tool designed to help students take greater control of their learning. An adaptable Open Education Resource currently available in English and French.

The goal of the present work was to conduct an evaluation of the module's effectiveness. With so many competing demands on students' and educators' time and priorities, evaluating the value of the module is critical to justifying its use and understanding under what conditions it has a benefit (25). Moreover, the present evaluation explores the perceived impacts of the module for different types of students and thus, addresses issues of equity and inclusion in learning environments. We piloted the module and accompanying evaluation were piloted in science, mathematics, and engineering courses, representing challenging courses in which failure and withdrawal rates can be high $(26,27)$, despite the importance of STEM disciplines (28-33). We then used the results of the pilot and its evaluation to iteratively improve the module, the present evaluation, and identify future areas of study, ultimately to improve students' learning abilities.

In the following sections, we describe the key concepts taught in the module that relate most closely to the present evaluation: metacognition, goal-setting, growth mindset, and mindfulness.

\section{Metacognition}

Metacognition has two components: (i) metacognitive knowledge and (ii) metacognitive control and regulation (Fig 2). Metacognitive knowledge is the awareness of one's own knowledge and thought processes. Metacognitive control and regulation involve a process where one chooses and monitors learning strategies that are appropriate for one's self based on their knowledge of their cognitive processes (34). In the module, students identify their current course-related knowledge and skills (and areas of deficit), values, and priorities, then set goals and make a plan to achieve those goals. As part of the module's activities, students are asked to rate their abilities on the course's intended learning outcomes, before and after major course assessments. 


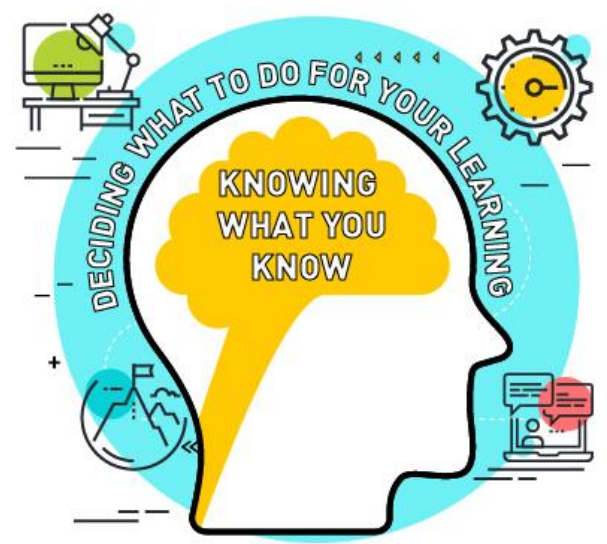

Fig 2. Metacognition: knowing what you know and choosing strategies accordingly.

Research has identified a relationship between high-performing individuals and high metacognitive skills $(35,36)$. For example, students' abilities to accurately monitor their knowledge positively correlates to their grade-point average (37). This finding suggests that higher metacognitive abilities may lead to success. At the same time, this finding may also suggest that higher success leads to higher metacognitive abilities (38).

Metacognition interventions to date have had mixed results (12,39-46). Studies have demonstrated that metacognition interventions improved participants' accuracy in predicting their abilities over time, known as calibration $(38,46)$. However, in another study, participants who practiced calibration accuracy did not show increased academic performance when compared to students who did not practice calibration accuracy when assessed on the same tests (47).

\section{Goal-setting}

Goal-setting theory and research suggest that productivity and motivation increase when specific goals exist (48-52). In the module, we address goal-setting using the SMART goal framework (Fig 3), an acronym that stands for Specific, Measurable, Accountable, Reachable, and Time-specific (slight variations of the SMART acronym exist). Students learn how to set goals that are sufficiently fine-grained so that the goals are broken-down into achievable subtasks in which students can gauge their progress and maintain motivation (53).
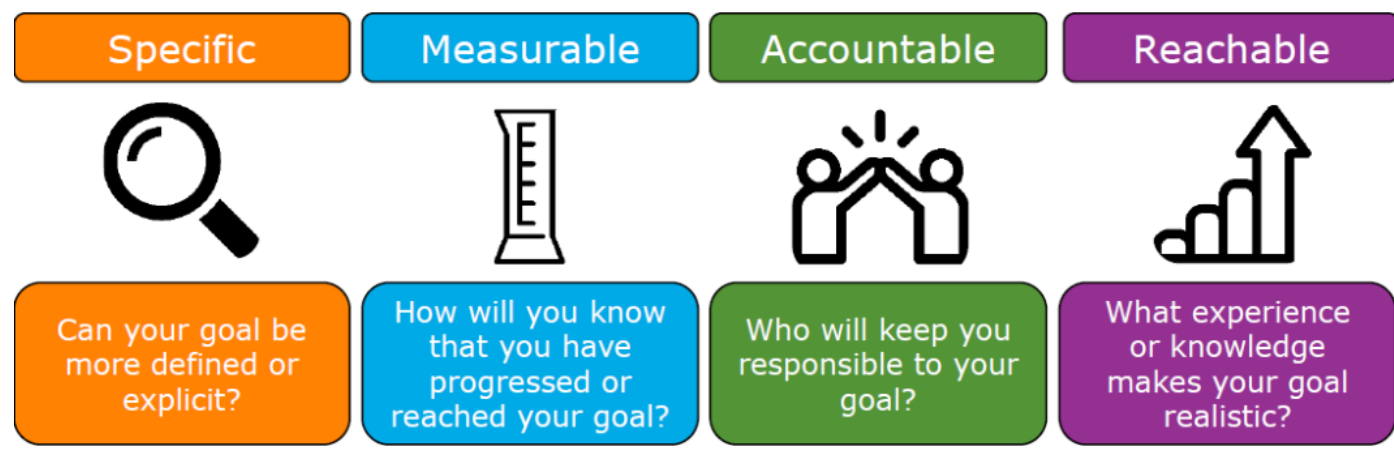

\section{Time-specific}

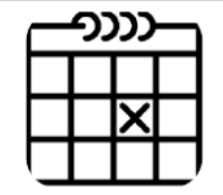

When will you

accomplish your

goal?

Fig 3. SMART goals and its five components are a framework for students to construct detailed, well-developed goals to aid in their progress through the SRL cycle. 


\section{Growth and fixed mindsets}

A person who holds a growth mindset is one who believes that intelligence is malleable and can be increased through appropriate effort and resilience in the face of failure. Conversely, a person with a fixed mindset believes that intelligence is hardwired and cannot be increased; its presence (or lack thereof) can only be measured (54-56). Growth and fixed mindsets exist on a continuum and can vary from one aspect of a person's life to another $(55,57)$. For example, a visual artist may feel strongly that their artwork improves through dedicated practice (growth mindset) but at the same time believe that they are incapable of ever understanding mathematics (fixed mindset) (24). Additionally, those with more of a growth mindset tend to have better academic results (57). The mindset of their educator can have an effect on the student's performance (58). Metacognition about mindset can bring greater control to students about their learning - with high metacognitive skill, they can identify their mindset for a given course or subject and control their mindset accordingly. Simple growth mindset interventions at scale can have positive impacts, but we must consider issues of context and population. However, the majority of studies in this area, to date, have focused on younger children rather than postsecondary students (59).

\section{Mindfulness}

Mindfulness is a practice that allows a person to develop present-time awareness of thoughts and feelings, and accept those thoughts and feelings as natural products of the mind that one can observe and can pass without becoming entangled, distracted, and off track (24). The module helps a learner develop mindfulness and loosen the control that their thoughts and feelings have over their behaviour, allowing students to focus on the things they choose to do. Research has found that mindfulness predicts self-regulated behaviour, essential for metacognitive regulation and control (60).

\section{Evaluation questions}

Below, we summarize the questions guiding this evaluation (Table 1). We developed these questions with key stakeholders (e.g., educators, students) using a Practical Participatory Evaluation (P-PE) approach (61-63). To guide the development we drew on the 4-level Kirkpatrick evaluation model, as we describe in the methods section below $(25,64)$.

Table 1. Evaluation questions.

\begin{tabular}{ll}
\hline Level & Evaluation question (EQ) \\
\hline 1: Reaction & $\begin{array}{l}\text { 1: What are the module's completion rates, based on students' demographics and course } \\
\text { incentives? }\end{array}$ \\
& $\begin{array}{l}\text { 2: How do students perceive the module? } \\
\text { 3: How do educators perceive the module? }\end{array}$ \\
\hline 2: Learning & $\begin{array}{l}\text { 4: To what extent do students achieve the module's intended learning outcomes (ILOs), } \\
\text { specifically those related to metacognitive skills, goal-setting, and mindsets? } \\
\text { 5: To what extent do students perceive that they will actually apply the learned } \\
\text { knowledge/skills? }\end{array}$ \\
\hline 3: Behaviour & $\begin{array}{l}\text { 6: What resources does the module require? } \\
\text { 7: To what extent do processes reinforce, monitor, encourage, and reward learning to apply } \\
\text { the learned knowledge/skills? }\end{array}$ \\
\end{tabular}


4: Results $\quad 8:$ What are the effects of the module on educators' teaching?

9: What elements of the module are transferable across academic disciplines?

10: What impacts does the module have on the institution's goals?

\section{Methods}

\section{Practical Participatory Approach and Kirkpatrick Model}

The present evaluation used both P-PE approach (61-63) and the Kirkpatrick evaluation model $(25,64)$.

A P-PE approach involves those who have a stake in the evaluand in all aspects of the evaluation process; from design to dissemination. As Cousins and Whitmore (1998) note, "the core premise of P-PE is that stakeholder participation in evaluation will enhance evaluation relevance, ownership, and thus utilization" (p. 6). This evaluation approach promoted deep participation and collaboration among key stakeholders (e.g., students, educators), provided high stakeholder control of decision-making, and included a diverse group of stakeholders. For this evaluation, we formed a team of stakeholders, including students, educators, learning support experts, academic support experts, and administrators. The team met annually over three years to develop and prioritize the major evaluation questions, including indicators, data sources, data collection methods, and bases of comparison for them. We used the P-PE approach incorporate and value the voices of various stakeholders, with the intent that the findings of the evaluation would be meaningful, applicable, and useful. (62).

Based on the suggestions from the above-mentioned stakeholders, we organized the evaluation questions using the Kirkpatrick evaluation model (25). This model evaluates innovations in today's learning environments, including its complexities (65). The model focuses on evaluating the following four levels: Reaction, Learning, Behaviour, and Results (Table 1). While many evaluation models are available (66-69), others have widely used the Kirkpatrick model to evaluate education programs $(64,65,69)$.

\section{Participants and context}

To date, over 5000 students at over 10 institutions in Canada and the United States have used the module since its launch in 2017. For the present study, we analyzed data from undergraduate students from a single, research intensive institution in Canada, enrolled in science, mathematics, and engineering courses that were taught either in English or French. One of these courses was taught during the 2020 pandemic.

\section{Data sources}

Data came from four main sources: the institution's Institutional Research Office, the module and course activities and assessments, focus groups, and educator questionnaires. The data came from nine French or English courses that used the module including chemistry, biopharmaceutical sciences, engineering, and mathematics courses at the first through fourth year levels. The courses are referred to as Course 1 - Course 9.

Students accessed the French or English versions of the module through the institution's learning management system (LMS) (2017-2018) and Pressbooks (2019 onward); they accessed 
the module's activities through the LMS (2017) and Google Drive activities (2018 onward) (21). In each course for which we used data, students completed the activities at the beginning of the semester, before and after midterm 1, before and after midterm 2 and before and after the final exam. The activities comprise a series of question types that include true/false, multiple choice, Likert scale, and open-ended questions.

We obtained anonymized demographic information from the Institutional Research Office. The categories represented herein represent the categories in which data were collected by the institution (e.g., male, female, other). The project was deemed ethics exempt by uOttawa's Research Ethics Board, in accordance with Canada's Tri-Council Policy Statement: Ethical Conduct of Research Involving Humans, Section 2.5 (70).

The module's activities were a core source of data, including student satisfaction and specific responses to metacognitive, goal-setting, and growth mindset questions. The total $\mathrm{N}$ for the study was 1845; however, not all data sets include the full number of responses for two main reasons: (i) students did not always answer all questions and (ii) some educators had altered the module (appropriately for their context), which made analyzing some results difficult (e.g., if a question had been modified) or impossible (e.g., if a question had been removed) to compare in some courses. We also held focus groups with the students and educators.

\section{Analysis methods}

Level 1 - Reaction

EQ1: To evaluate student completion rates, we considered the module "completed" by a student if they had participated in at least $70 \%$ of the module's activities. We removed data for students who dropped the course with the module or received an "incomplete" in the course (usually due to not completing the final exam, for a variety of reasons). We compared the percentage of students using the Growth and Goals module with the course incentive (if any), students' region of residence, first-generation status, program of study, and sex (self-reported at the time of registration, with the options: female, male, other). First generation students are those whose parents have never attended a college, CEGEP (Collège d'enseignement général et professionnel - equivalent to a community college), or university (71). Region of residence (home location) was the region where students reported living during the semester of studies. We did not compare language effects (i.e., students enrolled in French or English) were not compared, as only one course had used the module in French at the time, and the module had been incorporated mid-semester once translation from English was completed. We performed statistical analyses in $R$, using ANOVA tests and post-hoc $t$-tests with Bonferroni corrections.

EQ2: To evaluate students' perceptions of the module, we analyzed responses related to perceptions about the module from within the module's activities. We also conducted focus groups with students in courses that used the module. For the focus groups, students $(n=42)$ received information sheets about the evaluation and we randomly assigned students to a focus group. Each student received a \$20 Amazon gift card. The question guide can be found in the Supporting Information (SI). We audio- recorded the focus groups, transcribed them verbatim, and then completed a thematic analysis (72). 
EQ3: To evaluate educators' perceptions, we analyzed their responses to a questionnaire as well as those reported in a focus group with them. The focus group question guide can be found in the SI. Again, we audio- recorded the focus groups, transcribed them verbatim, and then completed a thematic analysis.

Level 2 - Learning

EQ4: To evaluate students' learning, we focus on their metacognition, goal setting, and mindsets.

Metacognition: Self-ratings of knowledge identify one key aspect of metacognition (knowing what you know); students' accuracy on those ratings identify students' metacognitive skill in that area. We evaluated students' metacognitive skills in one context by comparing their ability ratings with their actual results. For a single course (Course 5), we identified students who had provided a rating for all of the intended learning outcomes in a module activity before a major assessment and who completed the associated major assessment (midterm 1, $n=133$; midterm $2, n=119$; final exam, $n=102$ ). We summed the ratings to produce students' overall ILO scores, which were approximated as interval data. We also considered students' grades to be interval data. Thus, we compared each student's intended learning outcome score to their grade percentage on the associated major course assessment using a bivariate (Pearson's $r$ ) correlation analysis. Pearson's $r$ also serves as a measure of effect size where a value of $|0.1|$, $|0.3|$ and $|0.5|$ represent a small, medium and large effect size, respectively (73). Bias corrected and accelerated bootstrap 95\% confidence intervals are reported in square brackets in the results section.

Goal-setting: We used the score on a response to an in-module question was used to identify students' skills at identifying SMART goals; that question asked students to identify the SMART goal(s) in a set of four statements. To identify the quality of students' written goals, we analyzed a subset of responses to an in-module goal-setting question in depth from Course 5 , in which each student wrote three goals $(n=150)$. We analyzed each goal for whether it met each of the SMART goal criteria; we did not evaluate the goals for the nature or topic quality. We used students' highest score in the analysis to determine the average quality of students' goals and to investigate the correlation between the quality of the goal and students' final exam scores.

Mindsets: We analyzed students' abilities to differentiate between a series of growth and fixed mindsets in five courses $(n=600)$. For Course 5 , we analyzed the students' reported specific mindsets for that course's subject. At four times during the semester, students had been asked to rate to what extent they agreed or disagreed with ten mindset statements on a five-point Likert scale. We analyzed the responses from the students who completed all four activities ( $n=$ 101). For analysis, we converted the survey responses to a numeric value as follows: strongly disagree $=1$, disagree $=2$, neutral=3, agree $=4$, strongly agree $=5$. Since the students' response did not span the entire five-point range of the Likert scale, we used non-parametric tests to analyze the data (Friedman's analysis of variance). We conducted post hoc analyses using the Wilcoxon signed-rank test. To limit the number of statistical tests performed during the post hoc analyses and to analyze if changes in students' mindset were observed by the end of the semester, we performed Wilcoxon signed-rank tests only between students' agreement to mindset 
statements reported at the beginning of the course and those reported before the final exam. An $r$-value of $|0.1|,|0.3|$ and $|0.5|$ represent a small, medium and large effect size, respectively (73).

EQ5: We analyzed data from Courses 2 and 5 in depth to identify the ways in which students reported planning to used their knowledge and skills from the module. We also conducted a survey in a subsequent course that asked students who had previously used the module which of module's constructs they were using or planned to use, if any $(n=43)$. This subsequent course did not use the Growth \& Goals module.

Level 3 - Behaviour

EQ6 and EQ7: To evaluate behaviour, we analyzed educators' responses above-mentioned educator questionnaire as well as the focus group. In addition, we analyzed student data from the courses that incorporated the modules as well as students' responses to the student questionnaire described above. We also began to explore how students were actually using the module in future courses, even if those courses did not incorporate the module. To that end, we gave a survey in a course that followed one of the courses studied herein; that second course did not use the Growth \& Goals Module at the time.

Level 4 - Results

At the results level, we focused on the effects that the module had on educators' teaching by analyzing selected data from the above-mentioned focus group and questionnaire (EQ8-10). We also focused on the transferability of the modules across academic disciplines by exploring the nature of courses that incorporated the module (EQ9). Lastly, we investigate the impacts of the module on the University's goals (EQ10). Specifically, we analyzed the ways in which the module aligned with the institution's mission and provincial degree level outcomes.

\section{Results and discussion}

\section{Level 1: Reaction}

Completion rates varied by course incentives and students' demographics (EQ1) When a grade incentive as low as $1 \%$ was given either as part of the course grade or as a bonus, $76 \%$ of students completed the module ( $N=1845)$ (Fig 4). We observed lower participation was observed in courses with no associated mark (17\%) or when educators introduced the module late in the course (33\%). 


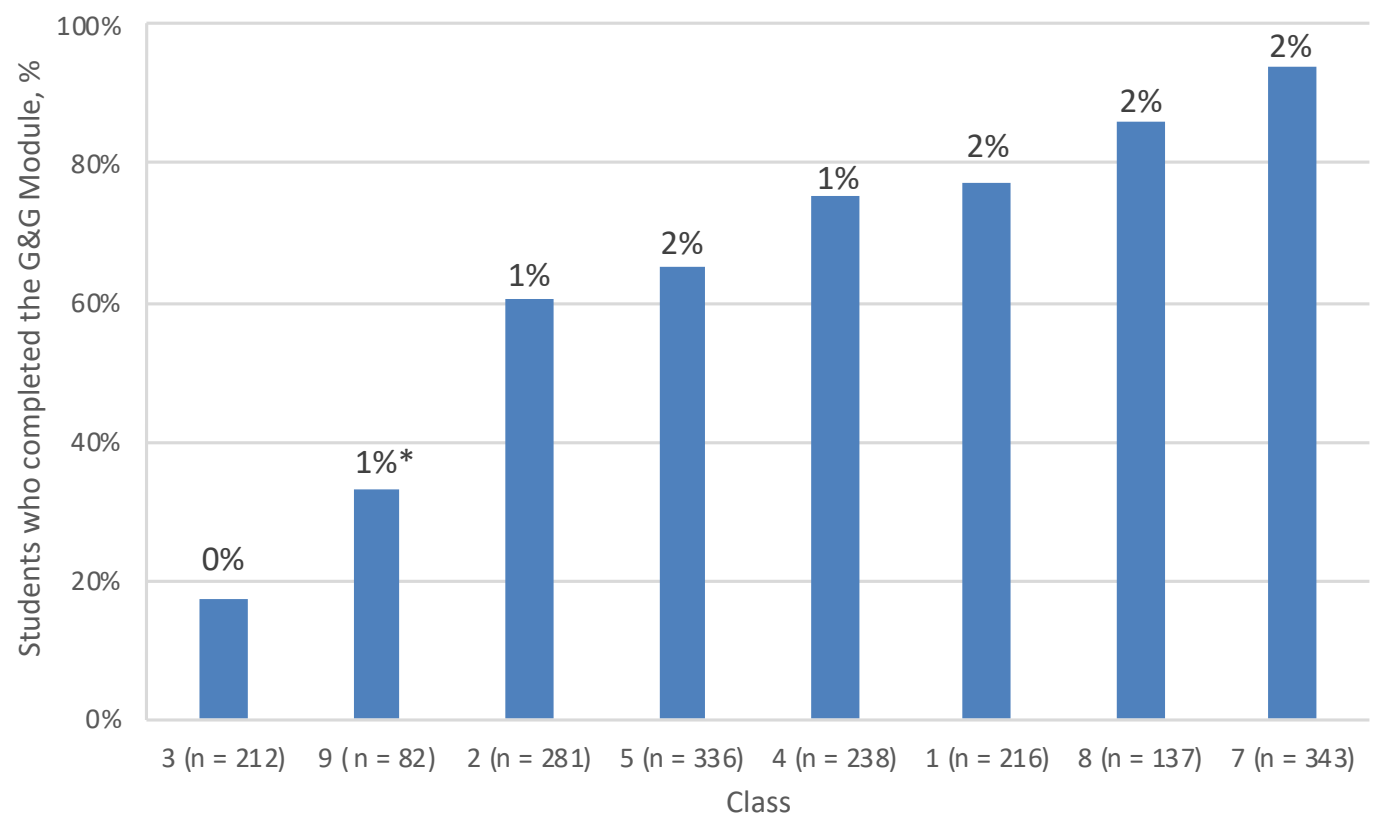

Fig 4. Percentage of students using Growth \& Goals module for each course in the study. Course names/codes were anonymized using arbitrary codes. Grade/Mark incentives (in \%) for the module's completion are indicated above each bar $(*=$ module was introduced late in the course). G\&G = Growth \& Goals.

Students living in the Ottawa-Gatineau region were most likely to complete the module; the greater the distance from the university, the lesser the likelihood of completing the module; $F(2,166.6)=5.412, p=0.001$ (Fig 6).

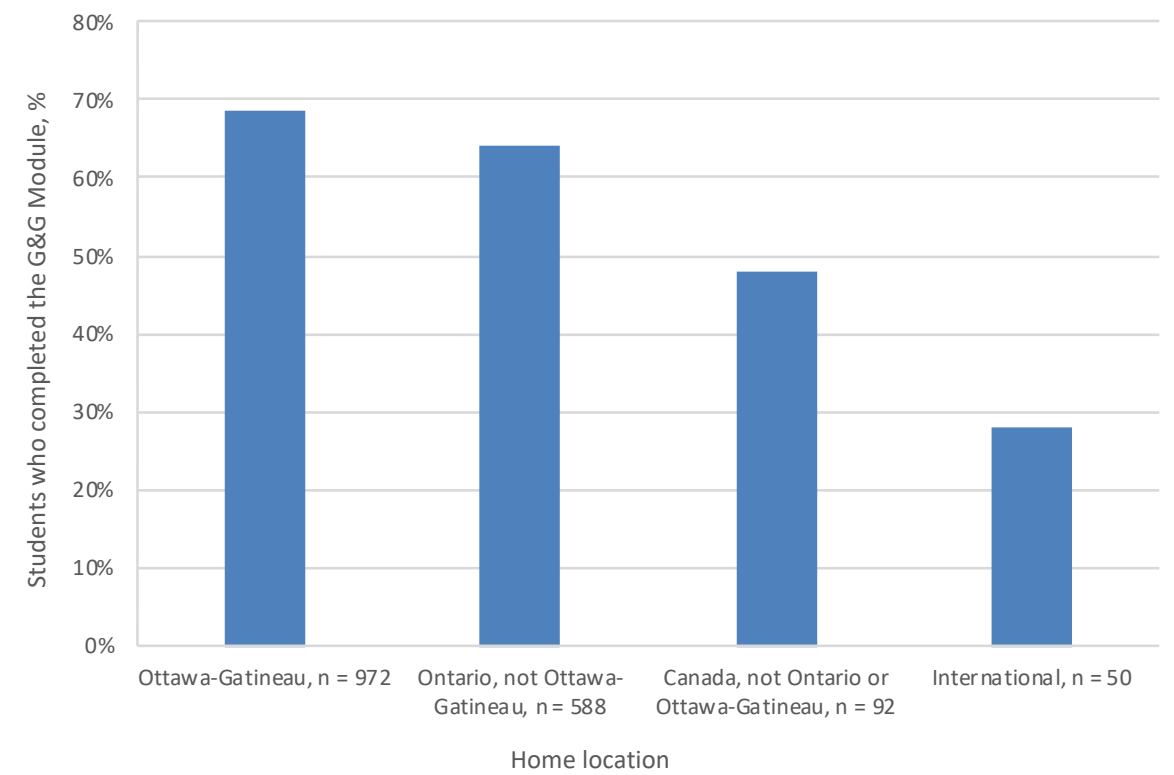

Fig 5. Percentage of students completing the Growth and Goals module based on the students' home location (region of residence). $n=1702$. 
Students in engineering and science programs had the highest completion rates, with the exceptions of chemistry and "other engineering" programs (Fig 7). Students in human kinetics and psychology programs were the least likely to complete the module. We saw a high proportion of special registration students completing the module, as they often have particular circumstances that may present barriers to their success at university. Further studies could explore why participation rates vary by program; possibly, the elite nature of the engineering and some science programs (e.g., biotechnology, biomedical sciences) means that students in those programs are already more motivated to succeed and therefore more likely to make use of the module to support their success. These programs may also be among the most challenging, in which students are motivated for grade supports (e.g., bonus marks).

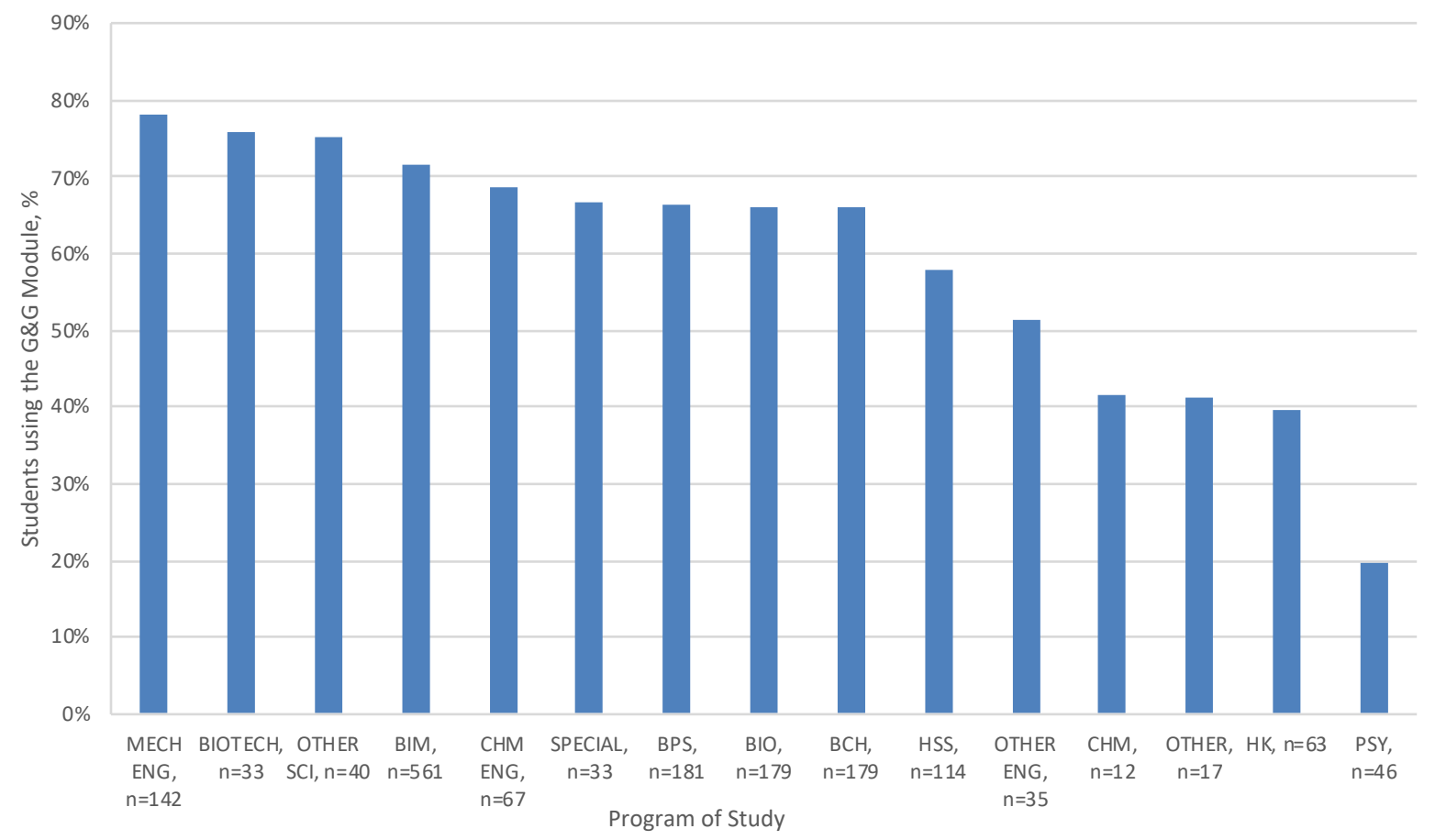

Fig 6. Percentage of students using the Growth and Goals module based on the students' programs of study. $n=$ 1702. BIOTECH=biotechnology, HSS=health sciences, MECH ENG=mechanical engineering, PSY=psychology, OTHER ENG=other engineering program, BIM=biomedical sciences, $\mathrm{CHM}=$ chemistry, BPS=biopharmaceutical sciences, OTHER=other program outside of the Faculty of Science, $\mathrm{HK}=$ human kinetics, OTHER SCl=other program in the Faculty of Science, $\mathrm{BIO}=$ biology, $\mathrm{BCH}=$ biochemistry, SPECIAL=special registration.

Students whose parents have a post-secondary education (PSE) were far more likely to complete the module (69\%) than students who parents do not have a PSE $(27 \%)$ or students who are unsure if their parents have a PSE (57\%) (Fig 8). This result is concerning as first 
generation students often face challenges that include understanding how university works, meeting expectations, and juggling academic, career, and personal responsibilities (71).

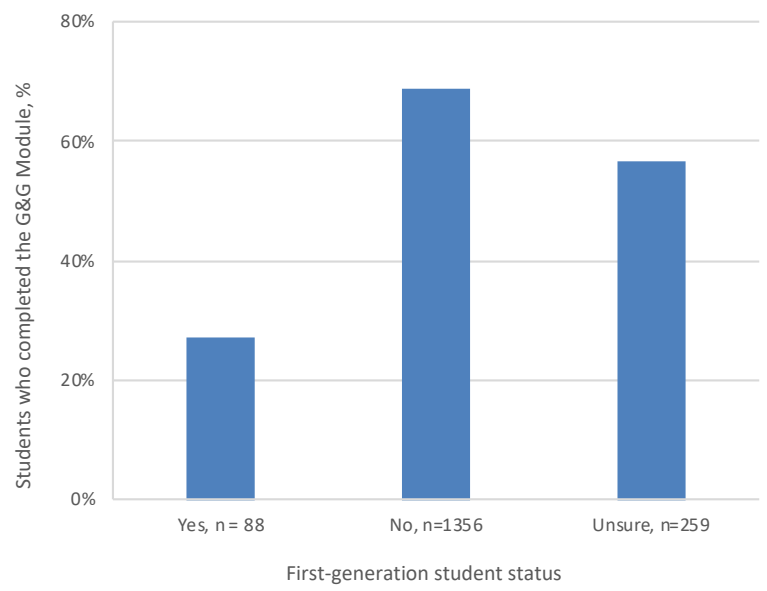

Fig 7. Percentage of students using the Growth and Goals module based on students' first-generation status. $n=$ 1703.

There was a significant effect of the student's sex on module completion, $F(2,1697)=12.03, p<$ 0.001 (Fig 9). Females completed the module more than males with a small effect size ( $p<$ $0.001, r=0.12$ ) although there was no significant difference between females or males and those who indicated "other" for sex $(p=0.45, p=1.00)$.

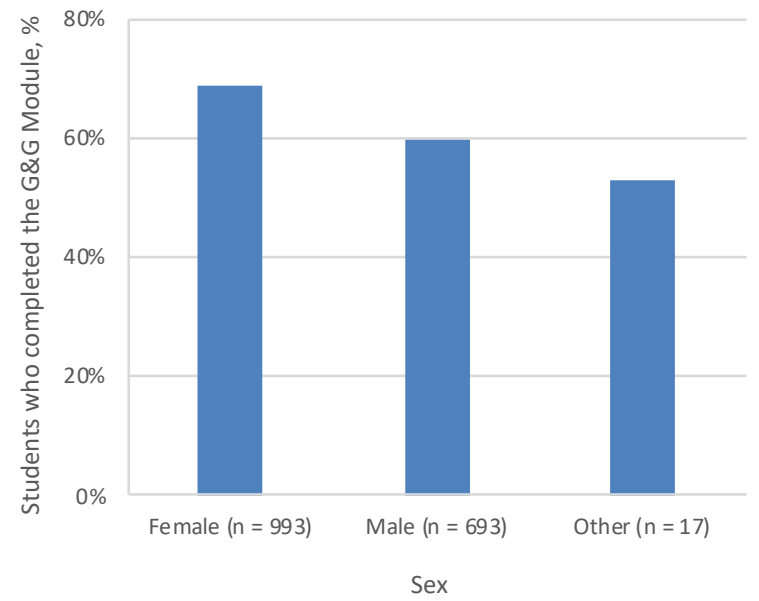

Fig 8. Percentage of students using the Growth \& Goals module based on sex. $n=1703$.

Overall, we found a number of differences in completion rates based on various demographic factors. To increase the number of students who complete the module, our next steps will be to further understand the reasons for these differences within various groups, so that we can address any barriers. For example, it may be that international students do not understand the reasons for developing learning skills in the context of a science course, if they are used to traditional approaches to learning sciences. 
The demographic groups who use the module most may perceive the module as more useful and engaging than the groups that use it less.

\section{Students' perceptions of the module were positive (EQ2)}

Students reported that the module was the first time most students had done explicit training in the learning skills addressed in the module $(88 \%, n=1120)$. Moreover, students' perceptions of the module were positive. For example, $59 \%$ believed the module would improve their learning $(n=983)$ and $65 \%$ believed the module would improve their awareness of their own knowledge $(\mathrm{n}=996)$.

Students' comments showed that they appreciated the module's constructs, such as going through their goals and breaking them down, reflecting on their mindsets, and rating their abilities on the learning outcomes. Students also mentioned that they appreciated being able to rate their abilities on the learning outcomes that they should have when entering the course (i.e., prior knowledge expectations). A number of students mentioned that this rating helped them identify course material to catch up on if they had forgotten aspects or had never learned them in a different institution. Students" comments included: "I like that a growth mindset makes you realize that it's okay to make a mistake and fix it later on.", "I think it kept you on top of things - oh man I really need to review that. I think it was the learning outcomes that made it really clear.", "It showed me resources I didn't really know about, like [academic support services]", "It was hard to write down things I wasn't good at. I'm glad I did, though, because later in the module I made a plan to improve those things.", and "When I put a zero for a learning outcome rating, that really made me think and work on that thing." (Fig 10).

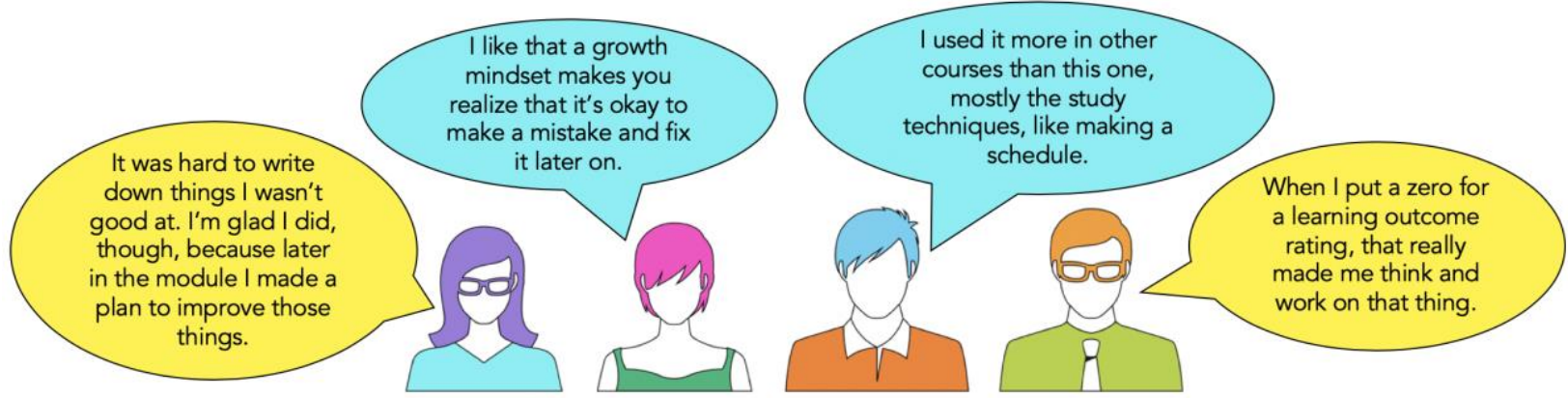

Fig 9. Selection of quotes from students who used the module and attended a focus group.

A minority of students reported not enjoying completing the module or that the time doing it detracted from their study time. We believe that a balance is needed between time to complete the module and study time. We do not think that the module will be useful for every student and some students may already be skilled learners; however, we do hope that developing explicit learning skills will help the majority of students become more proficient learners, even if they do not immediately see the benefit. As with learning anything new, time and effort are needed.

On the questionnaire and in focus group students suggested incorporating the module more into the course itself, adding more videos about concepts, providing an overview of other students' answers (e.g., most common study methods), making the module even more course 
specific, and simplifying the number of learning outcomes in the course (there were a few dozen in some courses). They recommended sharing evidence about the evaluation of the module, so that students were also made aware of the evidence associated with its use. They also recommended that the module's concepts be included on exams "so that we care about it more" and "are more likely to answer in depth versus just getting it done" - that recommendation is consistent with principles of constructive alignment: designing assessments that are aligned with the course's intended learning outcomes (ILOs) and values (74-76). Finally, they recommended that the module be expanded into levels, so that someone taking it could build on their learning skills as they gained expertise. Moreover, students recommended that we incorporate career strategy aspects into the module, especially when it is used in senior years. They indicated that such an approach would also minimize repetition for those who were exposed to the module in more than one course or year.

\section{Educators' perceptions of the module (EQ3)}

The majority of educators who have incorporated the module into their courses have continued to use it in subsequent years, an indication that the module has been favourably received in their courses. Most educators had used the module to create learning outcomes in their courses for the first time and appreciated the opportunity to do so. They also expressed the importance of the module being plug-and-play for educators who don't have experience teaching the module's constructs. The educators had similar comments to the students about wanting to incorporate the module into classes/lectures more and wanting to be able to show students how other students were studying; past data are now available for this purpose for professors who are using the module for the first time. Educators expressed the beliefs that the module has been positive for at least some and not detrimental to any.

We have already been able to address many of the educators' suggestions from the first version of the module, such as reducing the number of activities (reduced from 20 to 8-10), making the module easier to adapt (the Pressbooks version is much like working in a Word document), making the outputs easier (using Google Drive forms rather than the original version of the module's activities has made that easier). Some educators were not comfortable with students sharing their personal information with them, such as their values and thus, each of these questions can be readily adapted in the module, such as instructing students to write their answers in a personal notebook rather than in the activity.

Educators indicated concern about the bottom quartile of their course being less likely to participate-a concern that is born out in the data across courses (Fig 5). Here we also wish to explore methods to encourage students to engage in the module and are partnering with our University's academic success services to do so. Ultimately, however, it is students' decision whether to engage or not. Like students, educators expressed a desire to minimize repetition and incorporate skill-building/refining options for students who see the module in more than one course or year. They also suggested making the module into a program-level initiative, an idea that we are actively pursuing. 


\section{Level 2: Learning}

This level examines students' measured learning as it related to the module, and their beliefs that they will apply that learning in future contexts.

On average, students who completed the module had a higher final grade $(M=6.20, S D=2.8)$ than those who did not complete the module $(M=5.17, S D=3.1), t(1698)=(-6.76), p<0.001$ with a medium effect size, $r=0.20$ (Fig 5). There was also a large correlation $r=0.80$ between module completion and students' final grades.

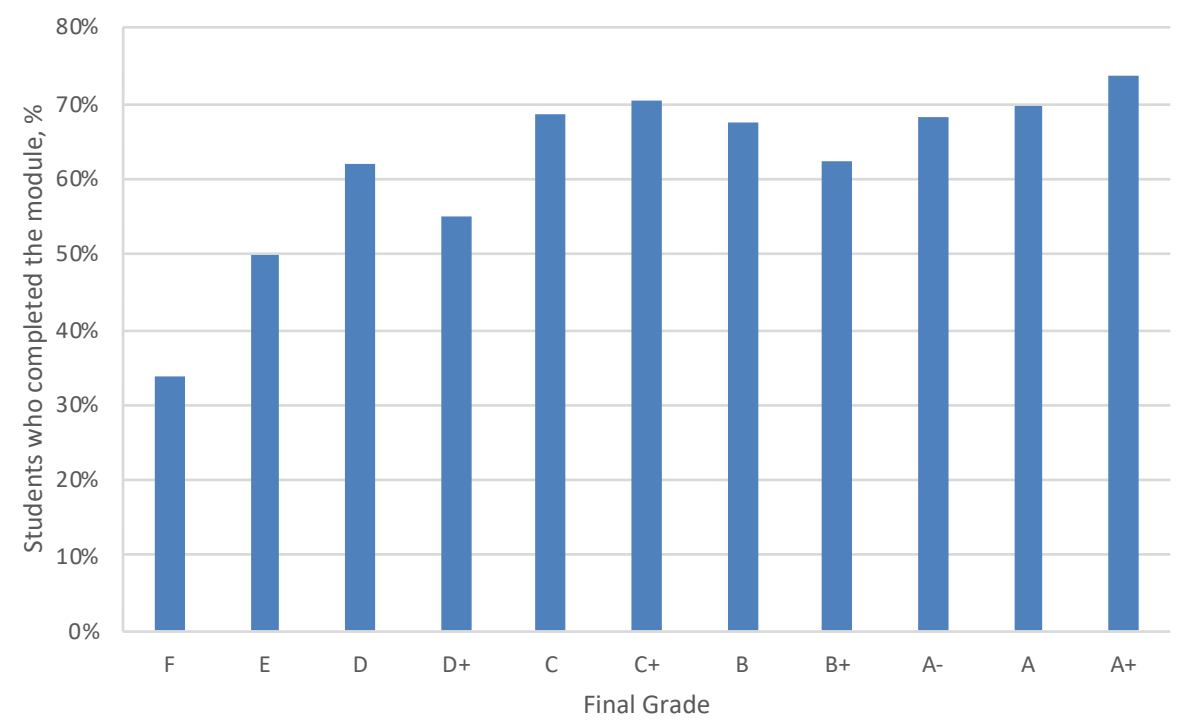

Fig 10. Percentage of students using the Growth \& Goals module, by final grade. $n=1700$.

The students achieved most of the module's intended learning outcomes (EQ4) The module's learning outcomes are listed in detail in the Intended Learning Outcomes section of the module; in this analysis, we focused on students' abilities related to three main constructs in the module: (i) metacognition, (ii) SMART goals, and (iii) growth mindset. We analyzed students' responses in the module's activities across courses. Using data from one course, we furthered the analysis related to metacognition and goal-setting.

(i) Improvement in metacognitive ability as the course progressed; Dunning-Krueger effect detected

Students' metacognitive ability was low early in the semester but improved as the course went on. Specifically, students' scores on Midterm 1 showed a significant correlation with their ability rating before that assessment, with a small to medium effect size, $r=0.255[0.077,0.410], p=$ $0.003, n=133$ (Fig 11a); Midterm 2 showed a significant correlation with their ability rating before that assessment, with a medium effect size, $r=0.308$ [0.119, 0.483], $p=0.001, n=119$ (Fig 11b); and the final exam showed a significant correlation with their ability rating before that assessment, with a medium to large effect size $r=0.460[0.316,0.593], p<0.001, n=102$ (Fig 11c). 

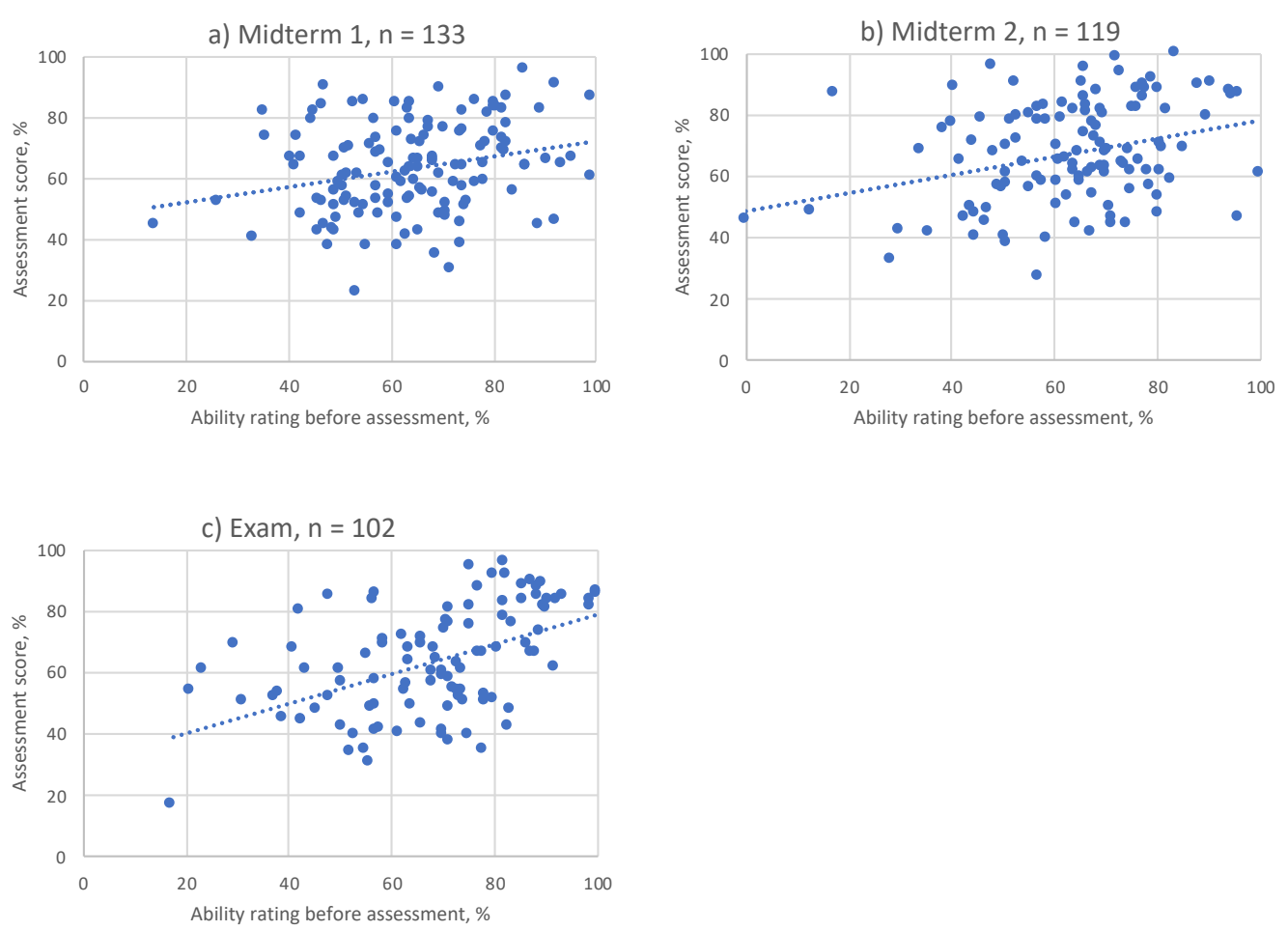

Fig 11. Comparison between course assessment scores and students' ability rating before each assessment. a) Midterm 1, $n=133(r=0.255)$, b) Midterm 2, $n=119(r=0.308)$, c) Exam, $n=102(r=0.460)$. Data from Course 5.

For Midterms 1 and 2, the self-ability ratings of the lowest-performing students was higher than their actual scores, representing over-estimation of their knowledge (Fig 12a and Fig 12b). Conversely, the self-ability ratings of the highest-performing students were lower than their actual scores, representing under-estimation of their knowledge. Both situations are consistent with the Dunning Krueger effect (77) and research in exam predictions. Each situation is undesirable, as students who overestimate their ability may prematurely stop studying in an area where they should be working, and students who underestimate their ability may spend too much time studying in a particular area. These metacognitive issues are problematic in a strategic sense: assuming each student is working hard, inaccurate self-knowledge ratings result in working hard in the wrong areas, rather than targeting the areas where they actually need work.

For the final exam, the ability ratings of low to highest-achieving students became accurate when compared to their actual scores (Fig 12c). The ability ratings of the lowest-performing students (i.e., those who achieved $1-25 \%$ on the exam) remained higher than their actual scores. The improvements in metacognitive skills for higher achieving students converges with prior research that found that higher-performing students' accuracy improved with explicit instruction (46). Research has found that incentives and tailored feedback can help lowerperforming students improve their metacognitive skills, becoming better calibrated as to their abilities (46). While we remain concerned that students with the very lowest course scores remained quite inaccurate, we are pleased to see the high prediction accuracy of students who achieve $26-100 \%$ on the assessment by the final exam. 

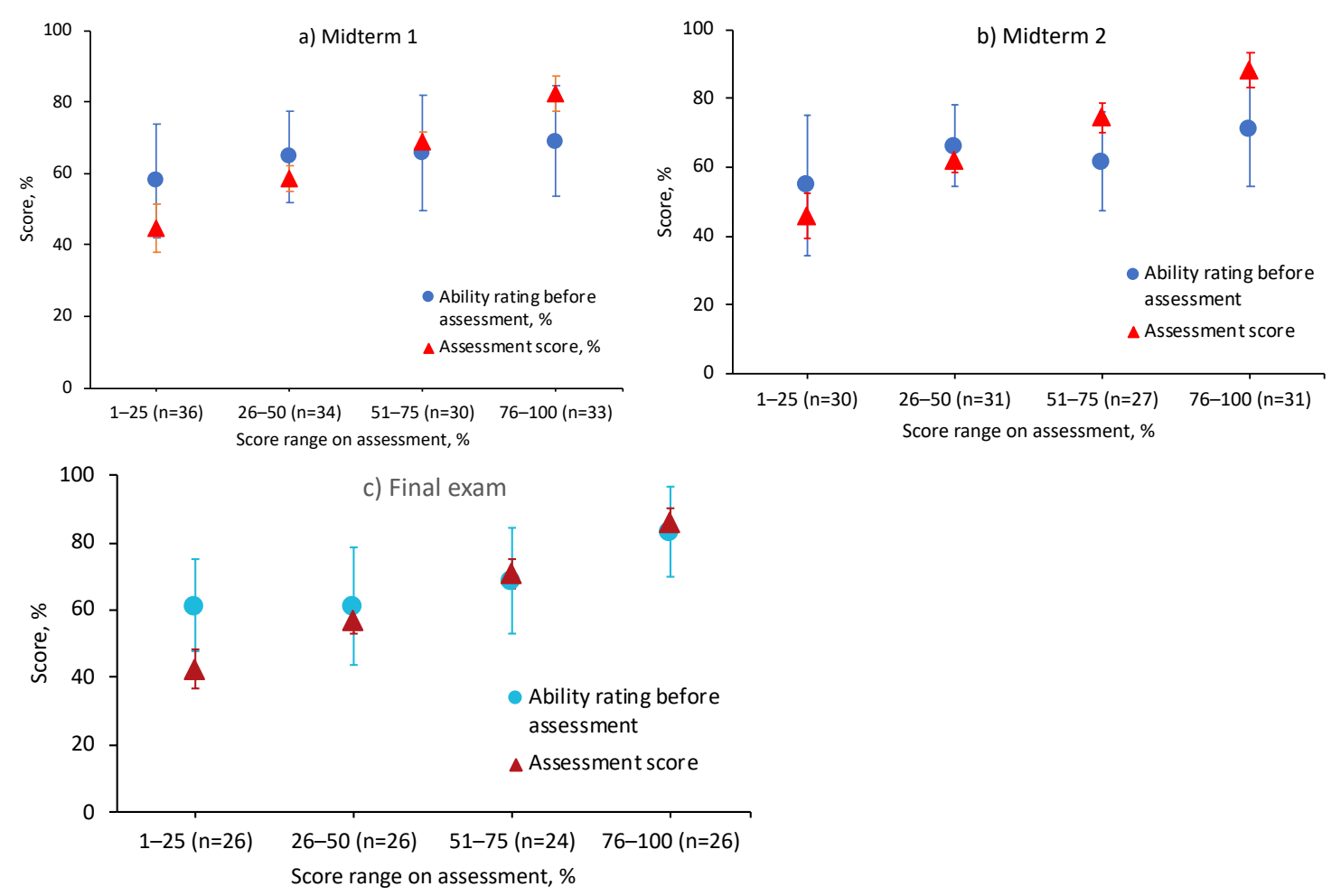

Fig 12. Students' ability ratings and actual scores for: a) Midterm $1(n=133)$, b) Midterm $2(n=119)$, and c) Final exam $(n=102)$ in Course 5. Error bars represent $+/-1$ standard deviation of the mean and the $n$-value below each bin represents the number of students in that score range.

\section{(ii) Small improvements in self-assessment methods}

We analyzed the methods that students reported using to gauge their own knowledge. Early in the semester and across courses, the top three ranked methods to assess their own knowledge were: reading over the section/chapter/slides, self-testing with previously seen questions, and using intuition/feeling (Fig 13). The lowest three ranked methods were: self-testing with neverbefore seen questions, explaining ideas to someone else and checking their understanding, and working with classmates to test each other.

Late in the semester, there was a slight shift in reported methods to self-assess knowledge, with "testing myself with problems I've never seen before" moving into the top 3, and "intuition/feeling" ranking $4^{\text {th }}$. Explaining ideas to someone else and working with classmates to test each other remained the lowest ranked methods. These findings were consistent across the five courses for which these data were available. From the early semester results, we were concerned that the prevalent study methods were the more passive ones, or using familiar questions. These methods most-used by students are not aligned with literature findings on successful self-assessment methods, which indicate that the first three methods are the least effective although they may feel the easiest and most comfortable; the latter three methods are the most effective (78). We were reassured somewhat to see an increase in self-testing with unfamiliar questions at the end of the semester, but remain concerned at the relatively high prevalence of passive reading and using "intuition/feeling" methods as ways of testing 
knowledge, as these are the least objective among the list. Moreover, peer learning could be much better leveraged to further self-knowledge assessment and, ultimately, learning (78).

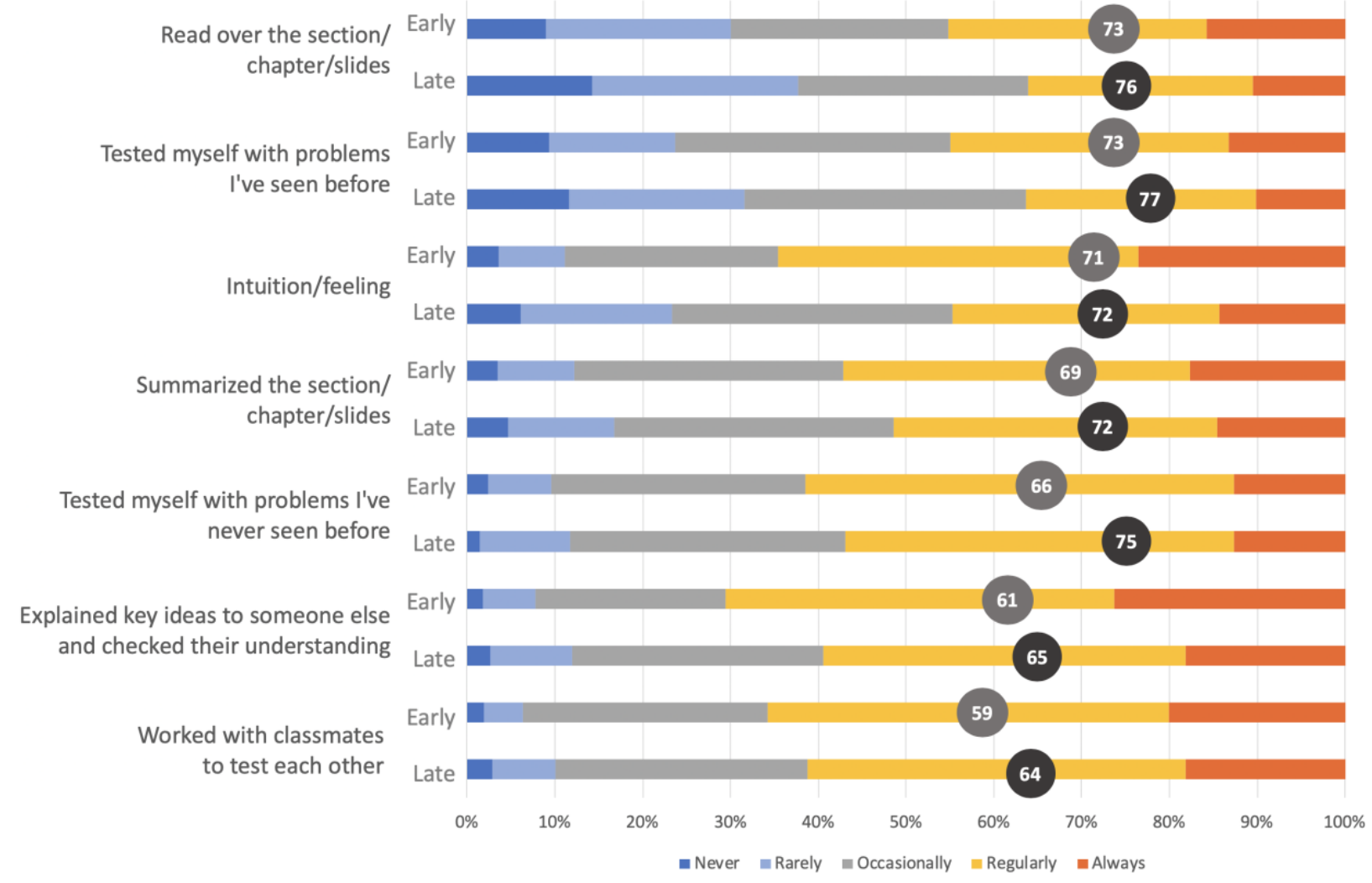

Fig 13. Methods that students used to self-assess their knowledge, early and late in the semester. Data from the 5 courses for which these data were available. Early semester, $n=704$; Late semester, $n=630$. Circled values represent weighted averages (light grey = early semester, dark grey = late semester); these are approximations since these data are categorical.

\section{(iii) Students could identify SMART goals but wrote more vague goals}

Students demonstrated a high ability to identify a SMART goal, based on in-module responses ( $M=88 \%, S D=19 \%, n=701)$. For one course, we analyzed the quality and content of the goals in depth. Quality was determined by deciding whether each of the SMART goal criteria were met in the student's written goal (5 points possible in total); the average was $49 \%$ (SD $=26 \%, n$ $=150$ ). The low stakes environment of the module could have led to lower effort in writing goals (lower extrinsic motivation) and that students may have written more specific goals in a higher stakes exam environment (higher extrinsic motivation). The topics of the goals spanned a range, with most being fairly large and distant (e.g., post-graduation and career), rather than finer-grained goals that would be achievable in a shorter time frame (Fig 14). 


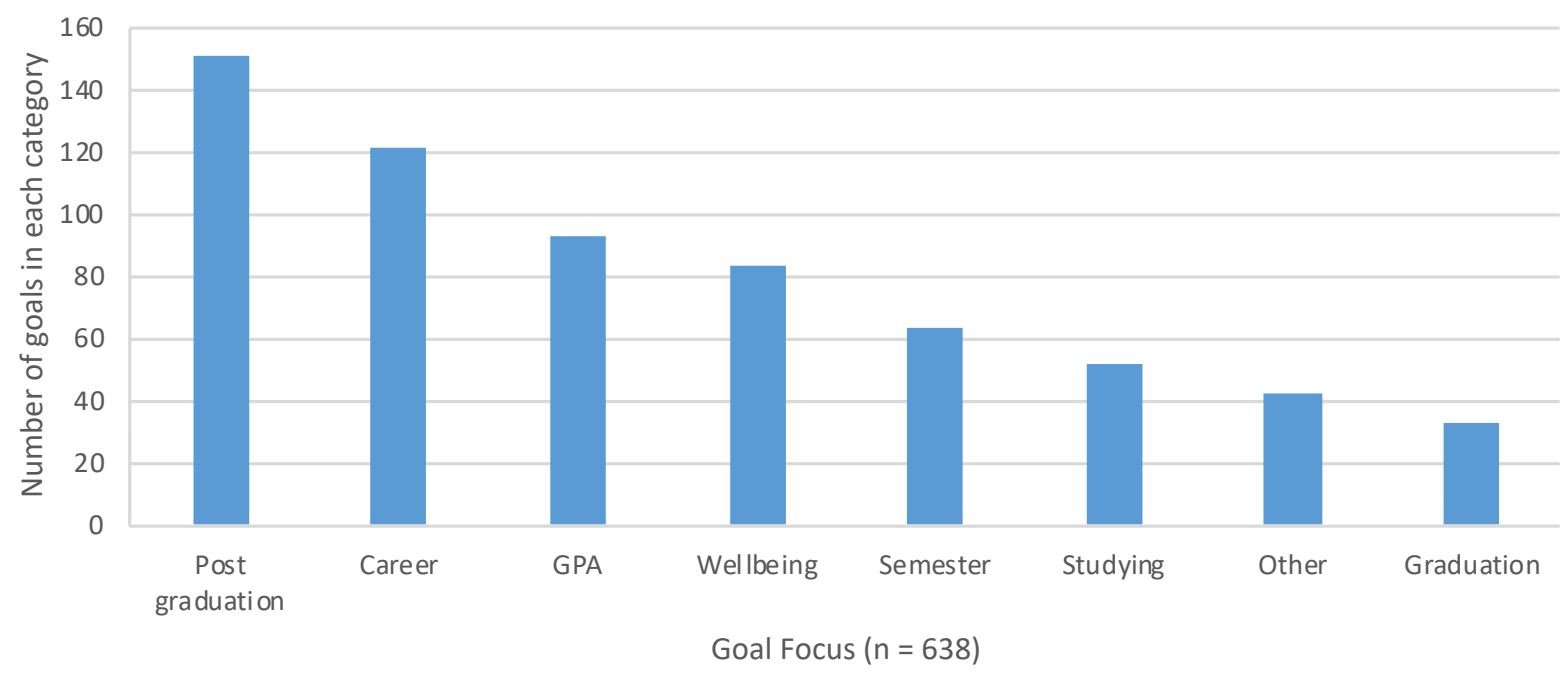

Fig 14. Main area of goals set by students in one course (Course 5). In that course, 638 goals were identified (in the goal-setting activities, students could set up to 3 goals).

Students who created SMART goals had a significantly higher pass rate than students who did not create any SMART goals, $t(48)=8.31, p<0.001, r=0.2$ (Fig 15). There was only a low correlation between the quality of the goal and the student's grade. Only $10 \%$ of students who created SMART goals failed the course $(<50 \%)$ compared with $59 \%$ of students who failed and course and did not create SMART goals (Fig 15). These findings could indicate that creating SMART goals helped students to succeed in their learning environment and accomplish more, and as a result, students obtained higher grades and passing rates. Alternatively, these findings could suggest that students who did not create any SMART goals were less motivated, and thus were already more likely to receive a low grade or fail the course due to their lack of motivation.

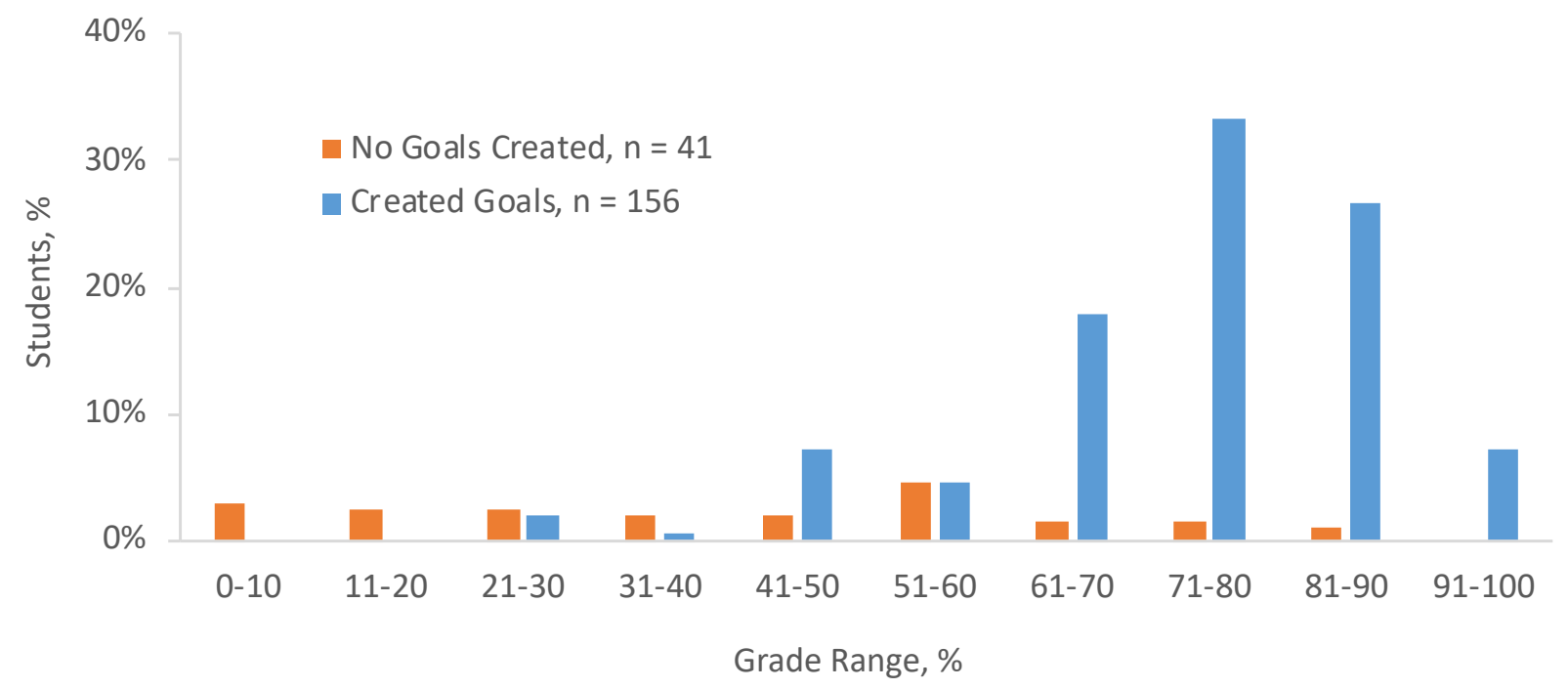

Fig 15. Percentage of students in each grade range, compared with whether they set goals in the module. Data are from Course $5(n=197)$. There was no correlation between the quality of the goal and the course grade (data not shown). 
(iii) High abilities in differentiating between growth and fixed mindset statements Over $92 \%$ of students gave correct responses to a question that asked them to differentiate between a series of growth and fixed mindsets $(n=600)$. When we analyzed students' responses to mindset statements specific to the course's subject, we found that students had shifted towards a growth mindset for six of the ten mindset statements, with no change in the other four statements. This finding suggests that overall, students shifted toward a growth mindset by the end of the semester with respect to that course. For example, in mindset statement 5: "I get help when I get stuck on a problem", students shifted towards a growth mindset by the end of the course (Fig 16). There was a significant change in the students' mindset during the semester, $\mathrm{X}^{2}(3)=14.74, p=0.002, n=98$. Post hoc analysis revealed students reported a statistically significant increase in agreement values before the final exam ( $M d n=4, I Q R=4-4)$ than at the beginning of the course $(M d n=4, I Q R=3-4)$ with a small to medium effect size, $z=-3.203, p<0.001, r=-0.2288$.

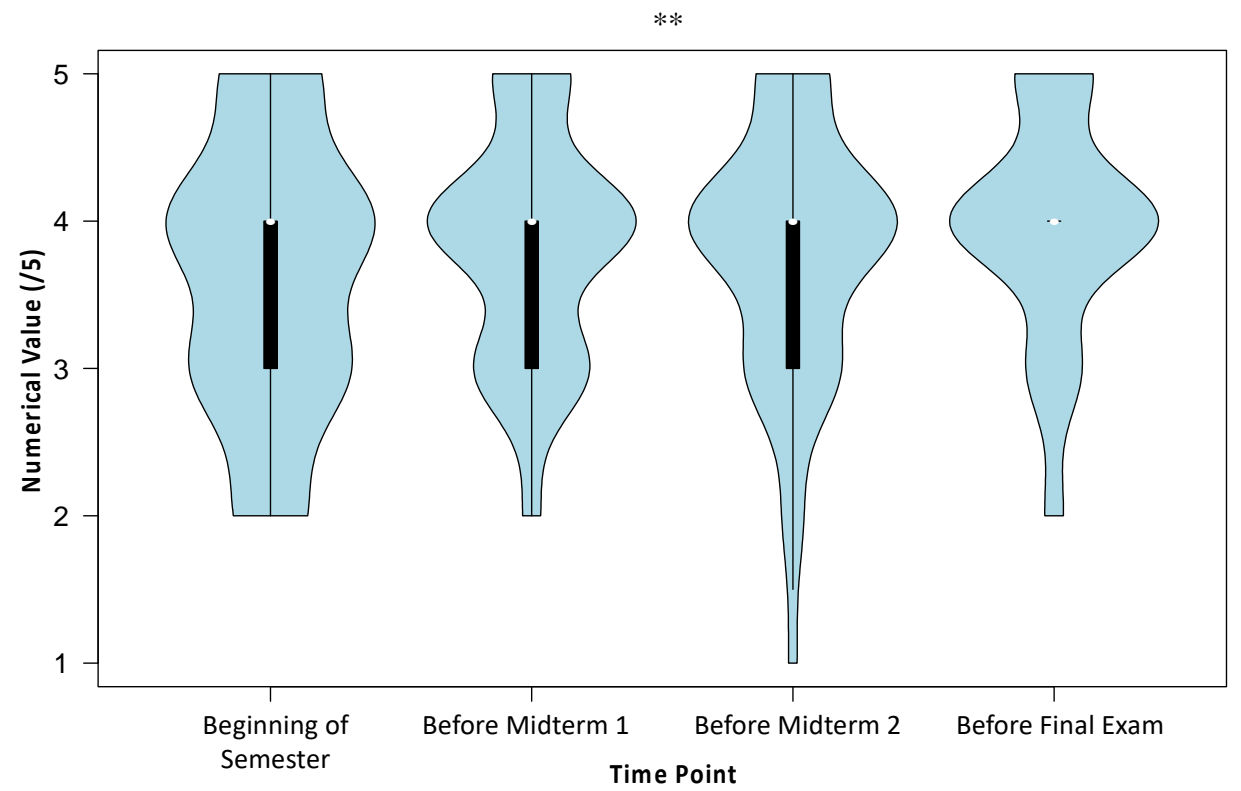

Fig 16. Students' agreement to mindset statement 5: "I get help when I get stuck on a problem" rated at four time points during the Fall 2017 semester. Students' responses were converted to numbers as follows: strongly disagree=1, disagree=2, neutral=3, agree=4, strongly agree. In the violin plot, the white circle indicates the median, the thick vertical line represents the interquartile range, and the width of each plot at each value is proportional to the number of responses of that value. ${ }^{* *}$ indicates a significant difference with $p<0.001$.

While we were pleased to see mindsets shifting toward growth throughout the course, we interpret these results cautiously. Growth/fixed mindsets are not inherently good or bad and relate to a specific area (e.g., academic, athletic, artistic) and not to ourselves as a person. For example, we may have a growth mindset about one aspect of our lives (e.g., learning math) and a fixed mindset about another (e.g., painting). Having a growth mindset about everything would make it nearly impossible to get anything done/learned. Analogously, having a fixed mindset about everything would hinder or prevent learning. The greatest benefit stand to come if we can be strategic about our mindsets, aligning them with our goals and priorities. Since we cannot place value judgements on students' goals (e.g., whether or not they should want to 
master a course in chemistry), we similarly cannot judge whether their mindsets are appropriate or not.

Most students believed they would apply the module's concepts (EQ5) Most students believed they would continue to use the module's concepts after completing the course (68\%, $n=987$ ) (Fig 17). At the end of the course, the module asked students to describe how they would use the knowledge and skills gained in the module in the future. We analyzed data from two of the courses to identify how students intended to use the knowledge attained (Course 5 and Course $8, n=380$ ). The most common response was that they would use the skills in other courses or their career in a general sense (22\%). Common answers also included: setting SMART goals (13\%), making a schedule (11\%), and using specific study strategies (9\%). Only $5 \%$ of students identified that they would apply the metacognition skills, a result that surprised us as metacognition forms the foundation of other skills (e.g., self-regulated learning, goal-setting). Students may have identified that skill implicitly or not realize the important role metacognition plays in setting related strategies. Similarly, they mentioned the application of self-regulated learning skills, mindset, and resources less often, perhaps for similar reasons or because other concepts were more important to them. Approximately $10 \%$ of students indicated that they would not use concepts from the module at all; that result bears further exploration since it's hard to imagine learning not involving any of these concepts.

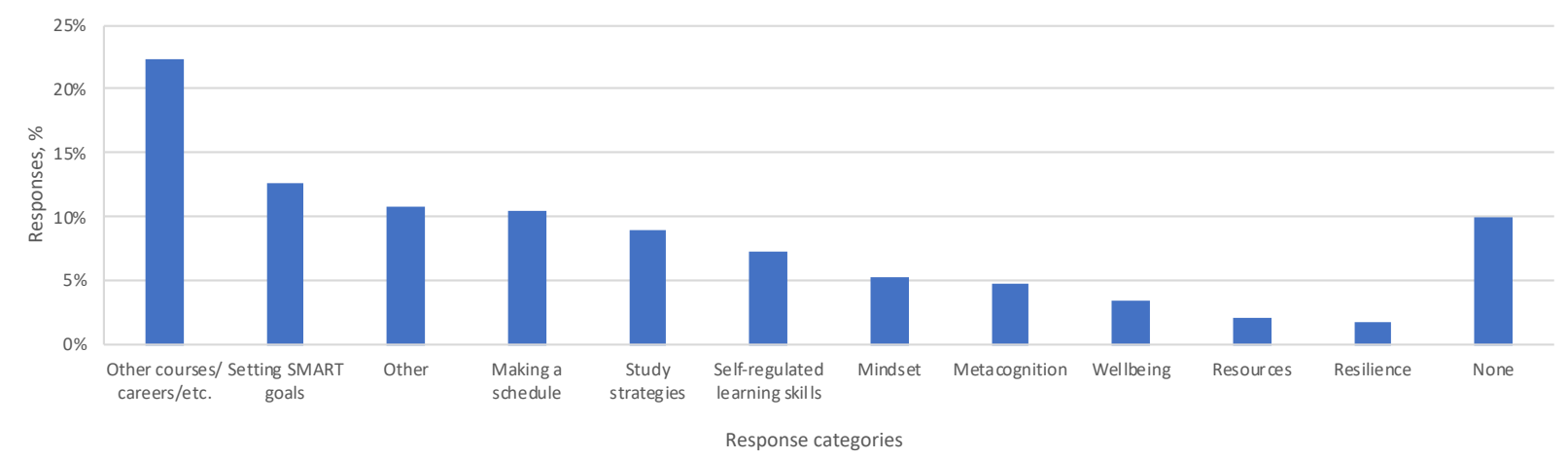

Fig 17. Predominance of responses to the end-of-course module question: "How will you use the knowledge or skills gained in the Growth \& Goals Module in the future?". Data analyzed from two courses (Courses 5 and 8, n = 380).

We also began to explore how students were actually using the module in future courses, even if those courses did not incorporate the module. The questionnaire results indicated that $97 \%$ of students were still using or planning to use the module's constructs ( $n=43)$. While preliminary, these findings are encouraging.

\section{Level 3: Behaviour changes}

Resources required to use the module (EQ6)

Incorporating the module in the course requires relatively little time on the part of the educator -one to four hours to adapt a template-and no knowledge in the module's constructs (Fig 18). Ideally, the educator will develop and incorporate the course's intended learning outcomes into the module, as these provide an important foundation for students to develop and refine their metacognitive skills, set goals, and plan strategies. Students and educators who have used 
the module recommend spending a few minutes in class periodically discussing the module. Otherwise, no major course changes are required. As an Open Education Resource that uses a Creative Commons license (CC-BY-NC-SA), the module is free and completely adaptable; it is available in French and English and can be used in its default browser format or in other exportable formats such as PDF, Kobo, or Word $(21,22)$. Instructions and support are available to educators, including periodic workshops and presentations (23). The module's activities are available by default as Google Forms (also adaptable to other formats), which export to spreadsheets that can be used to connect with a learning management system. Moreover, the module can be reused in future years without requiring additional modification.
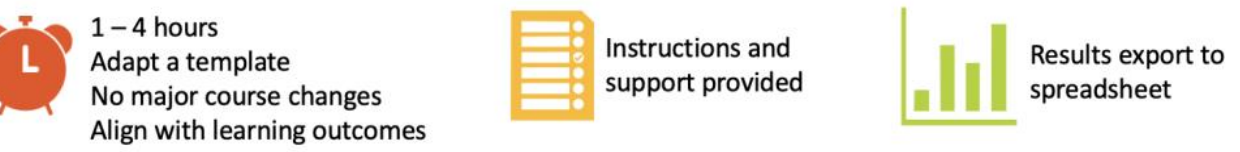

Reuse in future years

Fig 18. Key resources needed to incorporate the module in a course.

The module is similarly free for students to use, reducing barriers to use. Time is the major resource needed from students.

From the perspective of the project team, expanding the module's use and effectiveness requires time, people, and funding. The team gave more than two presentations at local, national, and international events. At most events, the team also held workshops for educators who chose to incorporate the module into their courses. To expand awareness of the module, team members have also been interviewed for media pieces, created infographics, produced videos, and written manuscript; these valuable contributions have only been possible through resources such as time, people, and funding, as well as in-kind contributions of production and research laboratories. Time: The development and knowledge mobilization team needs time to increase awareness of the module, support educators who incorporate the module, and provide technical support. The evaluation team also needs time to collect and analyze the data, meet to identify key research questions, data sources, and indicators. The project lead also needs time to connect with future potential project collaborators, to increase the module's quality, uptake, and scope (e.g., a program-level version). People: The project teams depend on strong team members, including students $(79,80)$, professors, academic support service experts, pedagogical experts (e.g., instructional designers), administrators, and other collaborators. Funding: Finally, the project needs funding, particularly to support student salaries ( $42 \%$ of original budget) and knowledge mobilization activities (32\%), with other funding needs including production costs for the module (19\%), research (5\%, gift cards for participants, software subscriptions), and translation costs (2\%).

Processes could be improved to reinforce, monitor, encourage, and reward learning to apply the learned knowledge/skills

By integrating the module with a course that the students are taking (i.e., meeting students where they are), the goal is to increase relevance and applicability of the module. A course incentive promotes high completion rates (Fig 4); discussing the module in class and including assessment questions related to the module (none personal) improve students' perceptions of the module's value. 
We find there is a lack of other kinds of motivation and rewards to truly master these skills, i.e., to change habits and behaviours. Incentives for correct and accurate answers may prove helpful (46), as could integrating the module within a program to build skills over time. Moreover, the main motivator for professors is the desire to better support student learning. There is not external motivation or incentive, and they need to take time to incorporate it, even if that time is low.

\section{Level 4: Results}

\section{Effects of the module on educators' teaching (EQ8)}

We detected two major impacts: (i) many educators created learning outcomes for the first time-incorporating the module seemed to act as both a motivator and a method to be supported in creating the learning outcomes; (ii) educators wanted to better support students' learning and the module provided a way for them to do so. We will continue to explore educators' recommendations, beliefs, and approaches as the module's use expands.

The module is transferable across academic disciplines (EQ9)

To date, educators have used the module in courses in a number of disciplines, including the sciences, engineering, mathematics, education, and psychology (course-level data not yet available for the latter two course types). Educators report no issues with integration in those disciplines. Future work will explore the transferability to a greater range of disciplines and contexts.

Impacts does the module have on the institution's goals (EQ10) In the province of Ontario, the Ontario Council of Academic Vice presidents (OCAV) outlined a set of six degree level expectations (DLEs) for undergraduate and graduate students (81). Two of the DLEs are critical in helping students learn to learn and manage their responsibilities but are rarely explicitly taught: "Awareness of the limits of knowledge" and "Autonomy and professional capacity". The Growth \& Goals module directly addressed both, the first through explicit instruction and practice in metacognition skills, the second through skills development throughout the module (e.g., goal-setting, reflecting, planning, acting, mindfulness, growth mindset). Moreover, the University's mission includes transformative learning and agility; students who master learning skills will be better positioned to learn and adapt quickly to rapidly changing situations, such as the 2020-2021 pandemic. The module positively aligns with this mission, as it helps to equip students with these essential learning skills.

\section{Limitations}

We analyzed real course data in this study, which brings advantages of ecological validity but drawbacks of variations in questionnaire formats, changes over time, and lack of a control group $(82,83)$. However, we believe the trade-off is essential in this case, to understand how the module is integrated and adapted in real course settings. With this information, we can best support students' learning. Moreover, the simplicity of integrating the module in courses affords an opportunity to investigate, in multiple settings, how the module is enacted, experienced, and its effect. 
Students' may not have accurately reported their learning outcome ability ratings and agreement to mindset statements for a variety of reasons. First, there was no incentive for students to complete the activities accurately. Students received the grade incentive for completing the module regardless of whether they completed the activities accurately. Second, students had to rate their abilities for many learning outcomes, up to fifty in a few courses. Providing ratings for many learning outcomes can be a time-consuming task. Many students reported during the student focus group that the activities before the major course assessments were too long. Some students reported going through the activities as fast as they could, so that they could get back to studying for the major course assessment. Thus, students may have quickly inputted responses to the activities and may have not taken the time to assess whether or not their learning outcomes ability ratings were justified. Based on the presence of statistically significant correlations between learning outcomes ability scores and course assessment grades, we believe that, in general, students reported reasonable ability ratings in the course's intended learning outcomes, according to their metacognitive skill. We also believe that students' reports of agreement to the mindset statements were quite accurate because of the presence of a statistically significant correlation between mindset score and assessment performance, a relationship that is supported by the literature (84). Yet, the possibility that some students did not accurately report responses for various reasons exists in the data set. Providing incentives for accuracy may improve the results.

Although we found a number of correlations in the analysis of the module's use, these do not prove a causal link. For example, the statistically significant correlations between mindset score and academic performance does not necessarily mean having a growth mindset leads to academic success. There is always the possibility that academic success leads to a growth mindset (reverse causality). Or, another variable could be at play that is the casual factor (the third variable problem). For example, having high motivation could lead to having a growth mindset and also leads to academic success; in this case, high motivation would be the third variable. Reverse causality and the presence of a third variable are also potential explanations for the relationship between the correlation of ILO ability score and academic performance.

This evaluation is not longitudinal and so it provides information only about perceived behaviour change and preliminary results.

\section{Conclusions}

In this study, we evaluated the effectiveness of a new Growth \& Goals Module, a courseintegrated module that teaches critical learning skills, including: metacognition, goal-setting, growth mindset, and mindfulness (21-23). Mastering such learning skills are essential for students to be able to continually learn and adapt in our complex, dynamic world (1).

Using a Practical Participatory Evaluation approach and the Kirkpatrick Evaluation mocel, we investigated ten research questions aligned with Kirkpatrick's four levels (reaction, learning, behaviour, and results). We collected data from nine undergraduate courses in science, engineering, and mathematics $(\mathrm{N}=1845)$. 
In Level 1 (Reaction), students and educators reported high satisfaction and that this was the first time most students had done such training. Completion rates were high in courses that gave at least a one percent mark for using the module. However, students in some demographics used the module less than others (small to medium effect sizes), including: lower-achieving students, from outside the Ottawa-Gatineau area, male, in certain programs, and first-generation university students.

In Level 2 (Learning), we found that students started with quite low metacognitive skills, but these increased over a single semester. The Dunning-Krueger effect was observed early in the semester on exam predictions, in which lower performing students over-estimated their ability, and higher performing students under-estimated their ability. By the end of the semester, most groups were extremely accurate except the students with the very lowest exam grades (<25\%). Incentives for accuracy could be helpful to motivate students to make more accurate predictions $(46,85)$. Early in the semester, students reported using passive methods to selfassess their knowledge (e.g., intuition) but moved to more active methods by late in the semester (e.g., self-testing with unfamiliar questions). Relatively few students used social methods to self-assess their knowledge (e.g., explaining to a friend), despite that being a research-supported strategy (78). Most students could identify a SMART goal from a list (88\%), but demonstrated a lower ability to write one (49\%), with more than half of goals being broader and longer term (e.g., career related) than desirable for a SMART goal. Students who created SMART goals had a significantly higher pass rate than students who did not create any SMART goals. Finally, over $90 \%$ of students in all courses successfully differentiated between growth and fixed mindset statements, and we observed an overall shift in mindset toward growth (one course analyzed).

In Level 3 (Behaviour), we identified that relatively few resources are required of educators; the module is free, adaptable, requires low technical knowledge, and takes between one and four hours to incorporate in a course, depending on educators' desired level of tailoring. The major resources required of students are time (a few hours) and low technical knowledge; the module is free and uses common technologies (web browser and online survey tools). Research and development require sustained support. Future research evaluation efforts will require substantially more resources (e.g., time, personnel, funding). By integrating the module with a course that the students are taking, the module meets the students where they are rather than being a separate entity (e.g., workshop); the goal in doing so is to increase module's relevance, applicability, and number of students reached.

In Level 4 (Results), we found that (i) most educators created learning outcomes for the first time-incorporating the module seemed to act as both a motivator and a method to be supported in creating the learning outcomes and (ii) educators had wanted to better support students' learning and the module provided a way for them to do so. All evidence to date indicates that the module can be readily used in any discipline; no specific course format is required. The module addressed two provincial degree level expectations that are critical in helping students learn to learn and manage their responsibilities but are rarely explicitly taught: "Awareness of the limits of knowledge" and "Autonomy and professional capacity". Moreover, empowering students with learning skills addresses institutional goals of transformative 
learning and agility by equipping them to monitor their own knowledge and skills, ready to strategize and adapt as needed.

We conclude that the module teaches core learning skills in a way that is systematic, scalable, and explicit; moreover, as an adaptable Open Education Resource, the module can readily be adapted to any discipline at any level of postsecondary study. The module has now been used by over 5000 students at 10 institutions.

We are currently exploring options to expand the module to non-academic contexts using a recently-published course-independent version of the module [citations], including athletic and artistic settings. We are also investigating two new aspects to incorporate in the module: Indigenous Knowledge and resilience, through collaborations with experts in each area. In the next phases of this work, we are seeking to increase uptake of the module by using a combination of change theories (86), guidance from knowledge mobilization frameworks $(87,88)$, and financial support, as educational innovations require specialized approaches in order to spread past the innovators themselves (89).

\section{Data availability}

The module itself is available for analysis; there are course-integrated versions available in English and French $(21,22)$, and course-independent versions available in English and French $(90,91)$. Student data are not available for reasons of privacy.

\section{Acknowledgements}

This material is based upon work supported by uOttawa's Chair in University Teaching Program (2016-2019). We thank Jean-Luc Daoust for assistance with data gathering and statistical analysis. We thank Glen Loppnow for preliminary data analysis and helpful discussions. We thank the evaluation team members for providing guidance in developing the research questions and setting evaluation priorities.

\section{References}

1. World Economic Forum. The Future of Jobs Report 2020 [Internet]. 2020 [cited 2021 Jan 1]. Available from: https://www.weforum.org/reports/the-future-of-jobs-report-2020

2. Dennon A. Coronavirus Impacts on Students and Online Learning [Internet]. Best Colleges. 2020 [cited 2021 Jan 1]. Available from: https://www.bestcolleges.com/blog/coronavirus-impacts-on-students/

3. Mahdy MAA. The Impact of COVID-19 Pandemic on the Academic Performance of Veterinary Medical Students. Front Vet Sci [Internet]. 2020 Oct 6 [cited 2021 Jan 1];7:594261. Available from: https://www.frontiersin.org/article/10.3389/fvets.2020.594261/full

4. COVID-19 Social Science Lab. Socio-demographic and academic statistics of responses [Internet]. 2020 [cited 2021 Jan 1]. Available from: http://www.covidsoclab.org/globalstudent-survey/global-database/socio-demographic-and-academic-statistics-of- 
responses/

5. Kuhfeld M, Soland J, Tarasawa B, Johnson A, Ruzek E, Liu J. Projecting the Potential Impact of COVID-19 School Closures on Academic Achievement. Educ Res. 2020 Nov 1;49(8):549-65.

6. National Student Clearinghouse Research Center. Current Term Enrollment Estimates [Internet]. 2020 [cited 2021 Jan 1]. Available from: https://nscresearchcenter.org/current-term-enrollment-estimates/

7. Wagener B. Metacognitive Monitoring and Academic Performance in College. Coll Teach. 2016;64(2):47-54.

8. Baliram N, Ellis AK. The impact of metacognitive practice and teacher feedback on academic achievement in mathematics. Sch Sci Math. 2019;119(2):94-104.

9. Hofer BK, Yu SL. Teaching of Psychology Teaching Self-Regulated Learning Through a “ Learning to Learn " Course. 2003;

10. Zimmerman BJ, Moylan AR, Hudesman J, White N, Flugman B. Enhancing self-reflection and mathematics achievement of at-risk urban technical college students. Psychol Test Assess Model. 2011;53(1):141-60.

11. Bergey BW, Parrila RK, Laroche A, Deacon SH. Effects of peer-led training on academic self-efficacy, study strategies, and academic performance for first-year university students with and without reading difficulties. Contemp Educ Psychol. 2019;56(November 2018):25-39.

12. Bol L, Campbell KDY, Perez T, Yen CJ. The effects of self-regulated learning training on community college students' metacognition and achievement in developmental math courses. Community Coll J Res Pract. 2016;40(6):480-95.

13. Aronson J, Fried CB, Good C. Reducing the effects of stereotype threat on African American college students by shaping theories of intelligence. J Exp Soc Psychol. 2002;38:113-25.

14. Fink A, Cahill MJ, McDaniel MA, Hoffman A, Frey RF. Improving general chemistry performance through a growth mindset intervention: selective effects on underrepresented minorities. Chem Educ Res Pract [Internet]. 2018 [cited 2019 Mar 6];19(3):783-806. Available from: http://xlink.rsc.org/?DOI=C7RP00244K

15. Good C, Aronson J, Inzlicht M. Improving adolescents' standardized test performance: An intervention to reduce the effects of stereotype threat. J Appl Dev Psychol. 2003;24(6):645-62.

16. Paunesku D, Walton GM, Romero C, Smith EN, Yeager DS, Dweck CS. Mind-Set Interventions Are a Scalable Treatment for Academic Underachievement. Psychol Sci. 2015;26(6):784-93.

17. Cooke NJ. Knowledge elicitation. In: Durso FT, editor. Handbook of applied cognition. UK: Wiley; 1999. p. 479-509. 
18. Cullen J, Bryman A. The Knowledge Acquisition Bottleneck: Time for Reassessment? Expert Syst [Internet]. 1988 Aug [cited 2021 Jan 2];5(3):216-25. Available from: http://doi.wiley.com/10.1111/j.1468-0394.1988.tb00065.x

19. CAST. Universal Design for Learning Guidelines verssion 2.2 [Internet]. 2018 [cited 2020 May 9]. Available from: http://udlguidelines.cast.org

20. AODA. The Act (Accessibility for Ontarians with Disabilities Act) [Internet]. 2014 [cited 2020 Apr 13]. Available from: https://www.aoda.ca/the-act/

21. Flynn A, Campbell-Brown E, O'Connor E, Walsh E, O'Hagan F, Richard G, et al. Growth \& Goals: a course-integrated module to better equip students with learning skills [Internet]. 2nd ed. 2020. Available from:

https://ecampusontario.pressbooks.pub/growthandgoalscourse/

22. Flynn A, Campbell-Brown E, O'Connor E, Walsh E, O'Hagan F, Richard G, et al. Croissance et objectifs : un module intégré au cours pour mieux équiper les étudiants en compétences d'apprentissage [Internet]. 2020 [cited 2021 Jan 2]. Available from: https://ecampusontario.pressbooks.pub/croissanceetobjectifscours/

23. Flynn AB. Flynn Research Group: Growth \& Goals Module [Internet]. Flynn Research Group Website. 2020 [cited 2021 Jan 2]. Available from: http://www.flynnresearchgroup.com/growthgoals

24. O'Connor EK, Roy K, Flynn AB. Growth \& Goals: A course-integrated open education resource to help students increase learning skills. Can J Scholarsh Teach Learn. 2020;Submitted.

25. Kirkpatrick JD, Kirkpatrick WK. Kirkpatrick's Four levels of Training Evaluation. East Peoria, IL: Association for Talent Development; 2016.

26. Laverty JT, Underwood SM, Matz RL, Posey LA, Carmel JH, Caballero MD, et al. Characterizing college science assessments: The three-dimensional learning assessment protocol. PLoS One. 2016;11(9).

27. Mahaffy PG. Chemistry Education and Human Activity. In: García-Martínez J, SerranoTorregrosa E, Atkins PW, editors. Chemistry Education: Best Practices, Innovative Strategies and New Technologies. Weinheim: Wiley; 2015. p. 3-26.

28. Saner M. A Primer on Scientific Risk Assessment at Health Canada [Internet]. Health Canada; 2010 [cited 2019 Oct 2]. Available from: http://www.hc-sc.gc.ca/srsr/pubs/about-apropos/2010-scientif-ris/index-eng.php

29. Craven E. The business case for encouraging students to pursue a STEM education - The Globe and Mail [Internet]. The Globe and Mail. 2017 [cited 2019 Oct 2]. Available from: https://www.theglobeandmail.com/report-on-business/careers/leadership-lab/thebusiness-case-for-encouraging-students-to-pursue-a-stem-education/article34986218/

30. Brandon Miller, Jay Croft. Planet has only until 2030 to stem catastrophic climate change, experts warn. CNN [Internet]. 2018 Oct 8 [cited 2018 Oct 8]; Available from: https://www.cnn.com/2018/10/07/world/climate-change-new-ipcc-report- 
wxc/index.html

31. Intergovernmental Panel on Climate Change. IPCC Special Report on Global Warming of $1.5^{\circ} \mathrm{C}$ approved by governments [Internet]. 2018 [cited 2018 Oct 8]. Available from: http://www.ipcc.ch/news_and_events/pr_181008_P48_spm.shtml

32. Steffen W, Richardson K, Rockstrom J, Cornell SE, Fetzer I, Bennett EM, et al. Planetary boundaries: Guiding human development on a changing planet. Science (80- ) [Internet]. 2015 Feb 13 [cited 2018 Oct 8];347(6223):1259855. Available from: http://www.sciencemag.org/cgi/doi/10.1126/science.1259855

33. United Nations. Global Issues Overview [Internet]. 2018 [cited 2019 Oct 2]. Available from: http://www.un.org/en/sections/issues-depth/global-issues-overview/

34. Pintrich PR, Wolters CA, Baxter GP. Assessing Metacognition and Self-Regulated Learning. In: Schraw G, Impara JC, editors. Issues in the Measurement of Metacognition. Lincoln, NE: Buros Institute of Mental Measurement; 2000. p. 43-97.

35. Everson HT, Tobias S. The ability to estimate knowledge and performance in college: A metacognitive analysis. Instr Sci [Internet]. 1998 [cited 2021 Jan 1];26(1-2):65-79. Available from: https://link.springer.com/article/10.1023/A:1003040130125

36. Thiede KW, Anderson MCM, Therriault D. Accuracy of metacognitive monitoring affects learning of texts. J Educ Psychol [Internet]. 2003 [cited 2021 Jan 1];95(1):66-73. Available from: /record/2003-01605-006?doi=1

37. Tobias S, Everson HT. Knowing What You Know and What You Don't: Further Research on Metacognitive Knowledge Monitoring. College Entrance Examination Board. 2002.

38. Hacker DJ, Bol L, Horgan DD, Rakow EA. Test prediction and performance in a classroom context. J Educ Psychol. 2000;92(1):160-70.

39. Greene JA, Azevedo R. The Measurement of Learners' Self-Regulated Cognitive and Metacognitive Processes While Using Computer-Based Learning Environments. Educ Psychol [Internet]. 2010 Jan 1;45(4):203-9. Available from: http://www.tandfonline.com/doi/abs/10.1080/00461520.2010.515935

40. Pazicni S, Bauer CF. Characterizing illusions of competence in introductory chemistry students. Chem Educ Res Pr [Internet]. 2014 Jan 14 [cited 2016 Jan 27];15(1):24-34. Available from: http://pubs.rsc.org/en/content/articlehtml/2014/rp/c3rp00106g

41. Talanquer V. Concept Inventories: Predicting the Wrong Answer May Boost Performance. J Chem Educ [Internet]. 2017 Dec 12 [cited 2018 Nov 6];94(12):1805-10. Available from: http://pubs.acs.org/doi/10.1021/acs.jchemed.7b00427

42. Huff JD, Nietfeld JL. Using strategy instruction and confidence judgments to improve metacognitive monitoring. Metacognition Learn. 2009;4(2):161-76.

43. Tanner KD. Promoting Student Metacognition. CBE-Life Sci Educ [Internet]. 2012 Jun [cited 2019 Apr 22];11(2):113-20. Available from: https://www.lifescied.org/doi/10.1187/cbe.12-03-0033 
44. Miller TM, Geraci L. Training metacognition in the classroom: The influence of incentives and feedback on exam predictions. Metacognition Learn. 2011;6(3):303-14.

45. Rickey D, Stacy AM. The Role of Metacognition in Learning Chemistry. J Chem Educ [Internet]. $2000 \mathrm{Jul}$ 1;77(7):915-20. Available from:

http://pubs.acs.org/doi/abs/10.1021/ed077p915

46. Callender AA, Franco-Watkins AM, Roberts AS. Improving metacognition in the classroom through instruction, training, and feedback. Metacognition Learn [Internet]. 2016 Aug 1 [cited 2021 Jan 1];11(2):215-35. Available from: https://link.springer.com/article/10.1007/s11409-015-9142-6

47. Bol L, Hacker DJ, O'Shea P, Allen D. The Influence of Overt Practice, Achievement Level, and Explanatory Style on Calibration Accuracy and Performance. J Exp Educ. 2005;73.

48. Bandura A, Schunk DH. Cultivating competence, self-efficacy, and intrinsic interest through proximal self-motivation. 1981;41(3):586-98.

49. Latham GP. The motivational benefits of goal-setting. 2004;18(4):126-9.

50. Zimmerman BJ. A Social Cognitive View of Self-Regulated Academic Learning. J Educ Psychol. 1989;81(3):329-39.

51. Zimmerman BJ. Becoming a Self-Regulated Learner: An Overview. Theory Pract [Internet]. 2002 May [cited 2016 Oct 17];41(2):64-70. Available from: http://www.tandfonline.com/doi/abs/10.1207/s15430421tip4102_2

52. Zimmerman BJ. Investigating Self-Regulation and Motivation: Historical Background, Methodological Developments, and Future Prospects. Am Educ Res J [Internet]. 2008 Mar 1;45(1):166-83. Available from: http://aer.sagepub.com/content/45/1/166.full

53. Bandura A. Social foundations of thought and action: A social cognitive approach. Social Foundations of Thought and Action: A social cognitive approach. Englewood Cliffs, NJ, US: Prentice-Hall, Inc; 1986. (Prentice-Hall series in social learning theory.).

54. Dweck CS. Mindset: The new psychology of success. New York, NY: Random House; 2006.

55. Dweck CS, Leggett EL. A Social-Cognitive Approach to Motivation and Personality. Psychol Rev. 1988;95(2):256-73.

56. Robins RW, Pals JL. Implicit Self-Theories in the Academic Domain: Implications for Goal Orientation, Attributions, Affect, and Self-Esteem Change. Self Identity. 2002;1(4):31336.

57. Corradi D, Nicolaï J, Levrau F. Growth mindset and its predictive validity-do migration background and academic validation matter? High Educ. 2018;1-14.

58. Canning EA, Muenks K, Green DJ, Murphy MC. STEM faculty who believe ability is fixed have larger racial achievement gaps and inspire less student motivation in their classes. Sci Adv [Internet]. 2019 Feb 15 [cited 2019 Feb 20];5(2):eaau4734. Available from: http://advances.sciencemag.org/lookup/doi/10.1126/sciadv.aau4734

59. Yeager DS, Hanselman P, Walton GM, Murray JS, Crosnoe R, Muller C, et al. A national 
experiment reveals where a growth mindset improves achievement. Nature [Internet]. 2019; Available from: https://doi.org/10.1038/s41586-019-1466-y

60. Brown KW, Ryan RM. The Benefits of Being Present: Mindfulness and Its Role in Psychological Well-Being [Internet]. Vol. 84, Journal of Personality and Social Psychology. American Psychological Association Inc.; 2003 [cited 2021 Jan 1]. p. 822-48. Available from: https://pubmed.ncbi.nlm.nih.gov/12703651/

61. Cousins JB, Whitmore E, Shulha L. Arguments for a Common Set of Principles for Collaborative Inquiry in Evaluation. Am J Eval [Internet]. 2012;34(1):7-22. Available from: https://doi.org/10.1177/1098214012464037

62. Cousins JB, Whitmore E. Framing Participatory Evaluation. New Dir Eval. 1998;80:5-23.

63. Cousins JB, Chouinard JA. Participatory evaluation up close : an integration of researchbased knowledge - University of Ottawa [Internet]. Charlotte, NC: Cousins, J. B., \& Chouinard, J. A., Participatory evaluation up close: A review and integration of the research base, Charlotte, NC, ; 2012 [cited 2016 Feb 29]. Available from: papers3://publication/uuid/44501FDF-51F4-44D7-A772-AF7B1D082384

64. Praslova L. Adaptation of Kirkpatrick's four level model of training criteria to assessment of learning outcomes and program evaluation in Higher Education. Educ Assessment, Eval Account [Internet]. 2010 Aug 25 [cited 2018 Nov 28];22(3):215-25. Available from: http://link.springer.com/10.1007/s11092-010-9098-7

65. Moreau KA. Has the new Kirkpatrick generation built a better hammer for our evaluation toolbox? Med Teach [Internet]. 2017 Sep 2 [cited 2020 Dec 23];39(9):999-1001. Available from: https://pubmed.ncbi.nlm.nih.gov/28649887/

66. Frye AW, Hemmer PA. Program evaluation models and related theories: AMEE Guide No. 67. Med Teach [Internet]. 2012 May 19 [cited 2020 Dec 23];34(5):e288-99. Available from: http://www.tandfonline.com/doi/full/10.3109/0142159X.2012.668637

67. Stufflebeam DL. The CIPP [Context Input Progress Product] model for program evaluation BT - Evaluation models. In: Evaluation models. Boston: Kluwer-Nijhoff; 1983.

68. Frechtling J, Mark MM, Rog DJ, Thomas V, Frierson H, Hood S, et al. The 2010 UserFriendly Handbook for Project Evaluation [Internet]. National Science Foundation; 2010. Available from: papers3://publication/uuid/EBF0C695-5176-4969-B4CA-E15E70F44380

69. Kirkpatrick. Great Ideas Revisited. Techniques for Evaluating Training Programs. Revisiting Kirkpatrick's Four-Level Model. Train Dev. 1996 Jan 1;50(1):54-9.

70. Canadian Institutes of Health Research, Natural Sciences and Engineering Research Council of Canada, Social Sciences and Humanities Research Council. TCPS 2 - Tri-Council Policy Statement: Ethical Conduct for Research Involving Humans (2018) [Internet]. Government of Canada. 2018. Available from: http://www.pre.ethics.gc.ca/eng/policypolitique_tcps2-eptc2_2018.html

71. SASS - Student Academic Success Service U of O. Special programs [Internet]. [cited 2021 Jan 2]. Available from: https://sass.uottawa.ca/en/mentoring/student/special-programs 
72. Patton MQ. Qualitative Research \& Evaluation Methods. Los Angeles, CA: Sage Publications; 2014.

73. Field A. Discovering statistics using IBM SPSS statistics. Los Angeles, CA: Sage Publications Ltd.; 2015.

74. Biggs JB, Tang C. Teaching for Quality Learning. Maidenhead: Society for Research into Higher Education and Open University Press; 2007.

75. Biggs J. Constructive alignment in university teaching [Internet]. Vol. 1, HERDSA Review of Higher Education. [cited 2021 Jan 2]. Available from: www.herdsa.org.au

76. Collis KF, Biggs JB. Using The SOLO Taxonomy. Set Res Inf Teach [Internet]. 1986 Jan 1;2(4):4. Available from: http://www.nzcer.org.nz/nzcerpress/set/articles/using-solotaxonomy

77. Kruger J, Dunning D. Unskilled and Unaware of It: How Difficulties in Recognizing One's Own Incompetence Lead to Inflated Self-Assessments. J Pers Soc Psychol. 1999;77(6):1121-34.

78. Brown PC, Roediger HL, McDaniel MA. Make it stick : the science of successful learning. Cambridge, Massachusetts : The Belknap Press of Harvard University Press; 2014.

79. Flynn AB. Let's get more students to the decision-making tables in higher education | University Affairs. University Affairs [Internet]. 2020 [cited 2020 Jun 4]; Available from: https://www.universityaffairs.ca/opinion/in-my-opinion/lets-get-more-students-to-thedecision-making-tables-in-higher-education/

80. Carle MS, Deng JM, Huang D, Lapierre KR, Mesnic N, Bodé NE, et al. Engaging students as co-creators of course resources and learning experiences. New Dir Teach Learn. 2020;Accepted.

81. Ontario Universities Council on Quality Assurance. Appendix 1: OCAV's Undergraduate and Graduate Degree Level Expectations - Ontario Universities Council on Quality Assurance [Internet]. Quality Assurance Framework. 2019 [cited 2019 Jul 18]. Available from: http://oucqa.ca/framework/appendix-1/

82. Brewer MB, Crano WD. Research Design and Issues of Validity. Cambridge University Press; 2014. p. 11-26.

83. Abowitz DA, Toole TM. Mixed Method Research: Fundamental Issues of Design, Validity, and Reliability in Construction Research. J Constr Eng Manag [Internet]. 2010 Jan 27 [cited 2021 Jan 2];136(1):108-16. Available from: https://ascelibrary.org/doi/abs/10.1061/\%28ASCE\%29C0.1943-7862.0000026

84. Kennett DJ, Keefer K. Impact of learned resourcefulness and theories of intelligence on academic achievement of university students: An integrated approach. Educ Psychol [Internet]. 2006 Jun [cited 2021 Jan 7];26(3):441-57. Available from: /record/200602372-007

85. Miller TM, Geraci L. Training metacognition in the classroom: The influence of incentives 
and feedback on exam predictions. Metacognition Learn [Internet]. 2011 Dec 12 [cited 2021 Jan 1];6(3):303-14. Available from:

https://link.springer.com/article/10.1007/s11409-011-9083-7

86. Reinholz DL, Andrews TC. Change theory and theory of change: what's the difference anyway? [Internet]. Vol. 7, International Journal of STEM Education. Springer; 2020 [cited 2021 Jan 1]. p. 2. Available from:

https://stemeducationjournal.springeropen.com/articles/10.1186/s40594-020-0202-3

87. Cooper A. RIPPLE: Mobilizing Research to Improve Education [Internet]. RIPPLE. 2013 [cited 2018 Oct 1]. Available from: http://www.ripplenetwork.ca/

88. Henderson C, Cole R, Froyd J, Khatri R, Stanford C, Friedrichsen D (Gilbuena). Increase the Impact [Internet]. 2016 [cited 2016 Jul 30]. Available from: http://www.increasetheimpact.com/

89. Lane AK, McAlpin JD, Earl B, Feola S, Lewis JE, Mertens K, et al. Innovative teaching knowledge stays with users. Proc Natl Acad Sci U S A [Internet]. 2020 Sep 15 [cited 2021 Jan 1];117(37):22665-7. Available from: https://sites.nationalacademies.org/cs/groups/dbassesite/documents/webpage/dbasse_

90. Flynn A, Brown EC, O'Connor E, Walsh E, O'Hagan F, Richard G, et al. Growth \& Goals: a module for any context, designed to develop learning skills [Internet]. Pressbooks; 2020. Available from: https://ecampusontario.pressbooks.pub/growthandgoalsindependent/

91. Flynn A, Brown EC, O'Connor E, Walsh E, O'Hagan F, Richard G, et al. Croissance et objectifs : un module pour tout contexte, conçu pour développer les compétences d'apprentissage [Internet]. Pressbooks; 2020. Available from: https://ecampusontario.pressbooks.pub/croissanceetobjectifsindependant/ 